\title{
High susceptibility of metastatic cells derived from human prostate and colon cancer cells to TRAIL and sensitization of TRAIL-insensitive primary cells to TRAIL by 4,5-dimethoxy-2- nitrobenzaldehyde
}

Hak-Bong Kim ${ }^{1,2}$, Mi-Ju Kim,2, Dae-Young Kim¹, Jae-Won Lee ${ }^{1,2}$, Jae-Ho Bae ${ }^{1,2}$, Dong-Wan Kim³ , Chi-Dug Kang ${ }^{1 *}$ and Sun-Hee $\mathrm{Kim}^{1,2^{*}}$

\begin{abstract}
Background: Tumor recurrence and metastasis develop as a result of tumors' acquisition of anti-apoptotic mechanisms and therefore, it is necessary to develop novel effective therapeutics against metastatic cancers. In this study, we showed the differential TRAIL responsiveness of human prostate adenocarcinoma PC3 and human colon carcinoma KM12 cells and their respective highly metastatic PC3-MM2 and KM12L4A sublines and investigated the mechanism underlying high susceptibility of human metastatic cancer cells to TRAIL.

Results: PC3-MM2 and KM12L4A cells with high level of c-Myc and DNA-PKcs were more susceptible to TRAIL than their poorly metastatic primary PC3 and KM12 cells, which was associated with down-regulation of c-FLIPL/S and Mcl-1 and up-regulation of the TRAIL receptor DR5 but not DR4 in both metastatic cells. Moreover, high susceptibility of these metastatic cells to TRAIL was resulted from TRAIL-induced potent activation of caspase-8, -9 , and -3 in comparison with their primary cells, which led to cleavage and down-regulation of DNA-PKcs. Knockdown of c-Myc gene in TRAIL-treated PC3-MM2 cells prevented the increase of DR5 cell surface expression, caspase activation and DNA-PKcs cleavage and attenuated the apoptotic effects of TRAlL. Moreover, the suppression of DNA-PKcs level with siRNA in the cells induced the up-regulation of DR5 and active caspase-8, -9 , and -3. We also found that 4,5-dimethoxy-2-nitrobenzaldehyde (DMNB), a specific inhibitor of DNA-PK, potentiated TRAIL-induced cytotoxicity and apoptosis in relatively TRAIL-insensitive PC3 and KM12 cells and therefore functioned as a TRAIL sensitizer.

Conclusion: This study showed the positive relationship between c-Myc expression in highly metastatic human prostate and colon cancer cells and susceptibility to TRAlL-induced apoptosis and therefore indicated that TRAIL might be used as an effective therapeutic modality for advanced metastatic cancers overexpressing c-Myc and combination of TRAIL therapy with agent that inhibits the DNA-PKcs/Akt signaling pathway might be clinically useful for the treatment of relatively TRAlL-insensitive human cancers.
\end{abstract}

\footnotetext{
* Correspondence: kcdshbw@pusan.ac.kr; ksh7738@pusan.ac.kr 'Department of Biochemistry, Pusan National University School of Medicine, Yangsan 626-870, South Korea

Full list of author information is available at the end of the article
} 


\section{Background}

Despite the improvement of therapeutic strategies against cancer, the acquisition of invasive/metastatic capabilities and the development of resistance to therapy in cancer cells are still critical problems for successful cancer therapy because recurrent or metastatic cancers that appear after the initial radiotherapy or chemotherapy are generally refractory to secondary therapies [1]. Some metastatic cancers are more resistant to chemotherapeutic drugs than their poorly metastatic counterparts as a result of their acquisition of anti-apoptotic mechanisms [2-5]. Therefore, it is necessary to elucidate the therapy-resistance mechanisms of metastatic cells for development of effective therapeutic modalities against metastatic cancers, since the molecular basis for the association of an aggressive metastatic phenotype with resistance to apoptosis is still unclear.

The death-inducing cytokine tumor necrosis factor (TNF)-related apoptosis-inducing ligand (TRAIL) holds enormous promise as an anti-cancer agent due to its highly selective apoptosis-inducing action on neoplastic versus normal cells [6,7]. The apoptosis signaling cascade is initiated through the engagement of the cell surface death receptors DR4 and/or DR5 by their ligand TRAIL. The binding of TRAIL to the death receptors leads to their trimerization and the recruitment of Fasassociated protein with death domain (FADD). Subsequently, FADD recruits the initiator procaspase- 8 or -10 , leading to the assembly of the death-inducing signaling complex (DISC), where the initiator caspases are autoactivated by proteolysis. Activated caspase- 8 or -10 then cleaves the effector caspase-3, resulting in the cleavage of the death substrates [8].

c-Myc is deregulated and over-expressed in many cancer cells. The deregulation of c-Myc confers a selective advantage on cancer cells by promoting proliferation, cell survival, and genetic instability, which can contribute to metastasis [9]. By contrast, the activation of cMyc dramatically sensitizes cells to the apoptotic action of TRAIL by up-regulating the cell surface level of DR5 and activating DISC, thereby playing an important role in determining cellular sensitivity to TRAIL [10]. The decision of a cell to undergo apoptosis or to promote cell survival by c-Myc depends on the specific cell type and the physiological status of the cell [11]. c-Mycdependent priming of the mitochondrial pathway is critical for the capacity of TRAIL-induced caspase- 8 signals to activate effector caspases and for the establishment of a lethal caspase feedback amplification loop in human cells $[12,13]$.

Recently, we demonstrated that metastatic cancer cells have an increased level and activity of DNA-PKcs, the catalytic subunit of DNA-dependent protein kinase (DNA-PK), compared with their primary cells [14], and
An et al. reported that DNA-PKcs regulates the stability of c-Myc through the Akt/GSK3 $\beta / c-M y c$ ubiquitination signal pathway [15]. In addition, it has been shown that the level of phosphorylated Ser-473 Akt was much higher in metastatic cancer cells than in non-metastatic cancer cells, and siRNA against Akt blocked cell migration, indicating that Akt activation is necessary for the metastasis of these cultured cells [16].

Therefore, we studied sensitivity of metastatic cancer cells to TRAIL and demonstrated the differential TRAIL responsiveness of two pairs of primary (PC3 and KM12) and metastatic (PC3-MM2 and KM12L4A) cells. PC3MM2 and KM12L4A cells were more susceptible to TRAIL than their poorly metastatic primary counterparts. This susceptibility was correlated with the up-regulation of cell surface DR5 and the prominent activation of caspases (caspase- $8,-9$ and -3 ) by TRAIL treatment, leading to the inactivation of the DNA-PKcs/Akt pathway through the cleavage of DNA-PKcs and the up-regulation of proapoptotic Bax.

\section{Results}

High susceptibility of metastatic cancer cells to TRAIL is mediated via DR5 and down-regulation of c-FLIP and Mcl1

To compare the susceptibility of TRAIL-induced apoptosis between of highly metastatic cells and their respective primary cancer cells with low metastatic potential, human prostate adenocarcinoma PC3 and its highly metastatic PC3-MM2 subline were treated with increasing concentrations of TRAIL. Interestingly, PC3-MM2 cells were significantly more sensitive to TRAIL-induced apoptosis and cytotoxicity than PC3 cells (Figure 1A). Similar results were obtained in the highly metastatic colorectal carcinoma KM12L4A cells and its primary KM12 cells. KM12L4A cells were significantly more susceptible to TRAIL-mediated apoptosis and cytotoxicity than KM12 cells (Figure 1B). These results indicated greater susceptibility of highly metastatic cells to TRAIL than their poorly metastatic primary counterparts.

Since it is well known that TRAIL triggers apoptotic signals via two types of death receptors, DR4 and DR5 [7], we examined whether the increased TRAIL-induced apoptosis in highly metastatic cells was mediated via DR4 and/or DR5 death receptors (Figure 2A). We found that treating PC3-MM2 cells with neutralizing antibody to TRAIL receptor DR5 prior to TRAIL treatment inhibited significantly TRAIL-induced apoptosis, while the neutralizing anti-DR4 antibody only slightly inhibited TRAIL-induced apoptosis in the metastatic cells. Similar results were obtained in KM12L4A cells. Therefore, to correlate the inhibitory effects of anti-DR5 neutralizing antibody on TRAIL-induced apoptosis in both PC3-MM2 and KM12 L4A cells with cell surface 


\section{A}

B
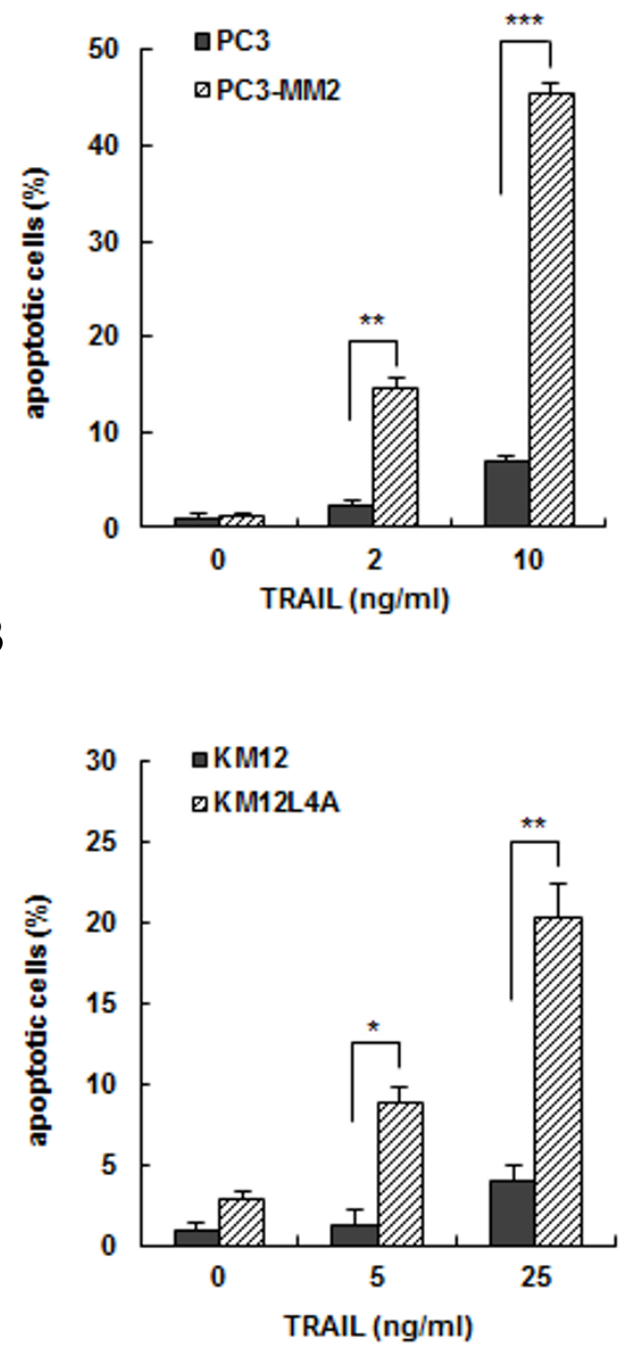

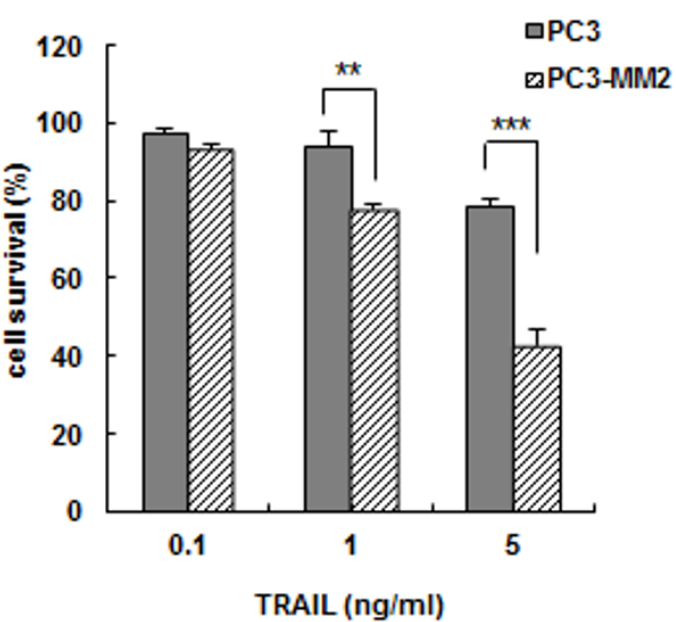

口KM12

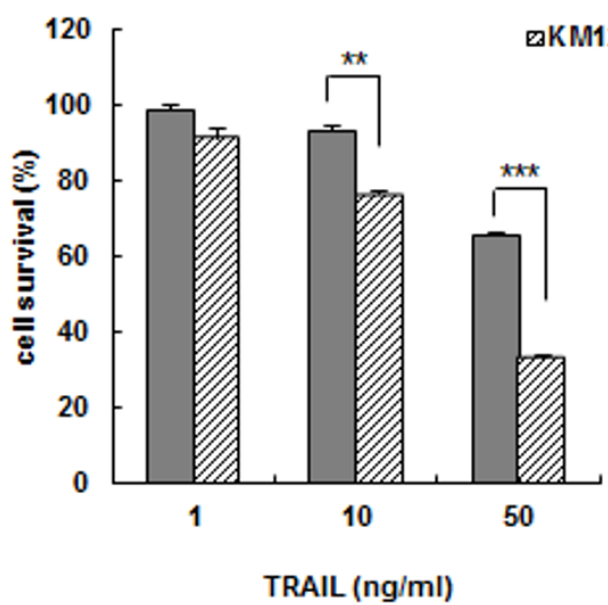

Figure 1 Differential TRAIL responsiveness of human prostate adenocarcinoma PC 3 and colorectal carcinoma KM12 cells and their respective highly metastatic PC3-MM2 and KM12L4A sublines. PC3 and PC3-MM2 cells (A) or KM12 and KM12L4A cells (B) were treated with the indicated doses of TRAIL for 6 or $8 \mathrm{~h}$, respectively, and the percentage of apoptotic cells in each cell population was determined using Annexin V staining and flow cytometry (left). In addition, PC3 and PC3-MM2 cells or KM12 and KM12L4A cells were treated with the indicated doses of TRAIL for $96 \mathrm{~h}$, and cell survival (\%) was determined using the MTT assay (right). Each value represents the mean \pm SE of triplicate determinants. ${ }^{*} p<0.05,{ }^{* *} p<0.01,{ }^{* * *} p<0.001$.

expression of DR5, we determined the cell surface expression of DR4 and DR5 in the metastatic cells. After treatment with TRAIL, the surface expression of DR5 was significantly up-regulated in both PC3-MM2 and KM12 L4A cells, whereas DR4 expression was not modulated by TRAIL treatment (Figure 2B). These results suggest that the increased susceptibility to TRAIL of highly metastatic cells may be attributed to TRAIL-induced up-regulation of DR5.

Since the expression of cellular FADD-like interleukin$1 \beta$-converting enzyme (FLICE)-inhibitory proteins

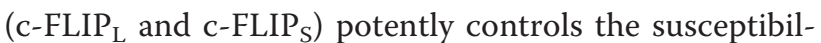
ity of cancer cells to TRAIL-induced apoptosis, we assessed the mRNA and protein levels of $\mathrm{c}-\mathrm{FLIP}_{\mathrm{L} / \mathrm{S}}$ in the metastatic cells treated with or without TRAIL using quantitative real-time RT-PCR and Western blot analysis, respectively. The results of quantitative real-time RT-PCR showed that basal mRNA levels of c-FLIP ${ }_{\mathrm{L} / \mathrm{S}}$ were significantly down-regulated in PC3-MM2 and KM12 L4A cells compared with PC3 and KM12 cells, respectively, and after treatment with TRAIL the mRNA levels of c-FLIP ${ }_{\mathrm{L} / \mathrm{S}}$ were significantly decreased in PC3- 
A

PC3-MM2

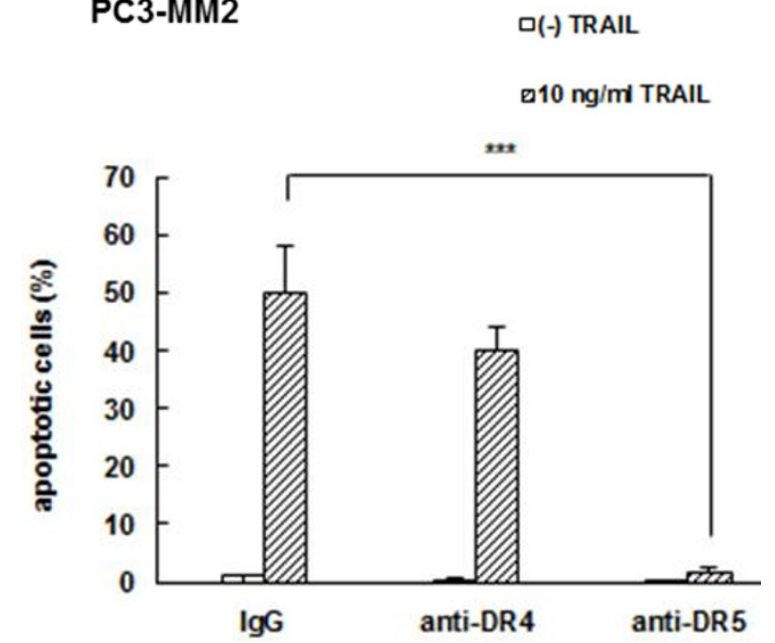

\section{KM12L4A}

Q(-) TRAIL

D25 ng/m TRAIL

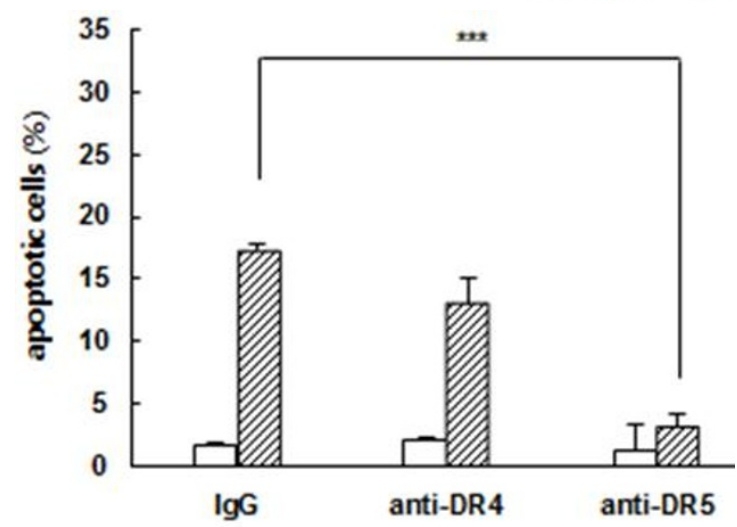

B

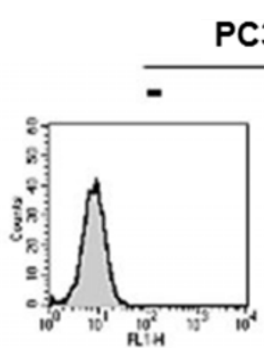

PC3-MM2
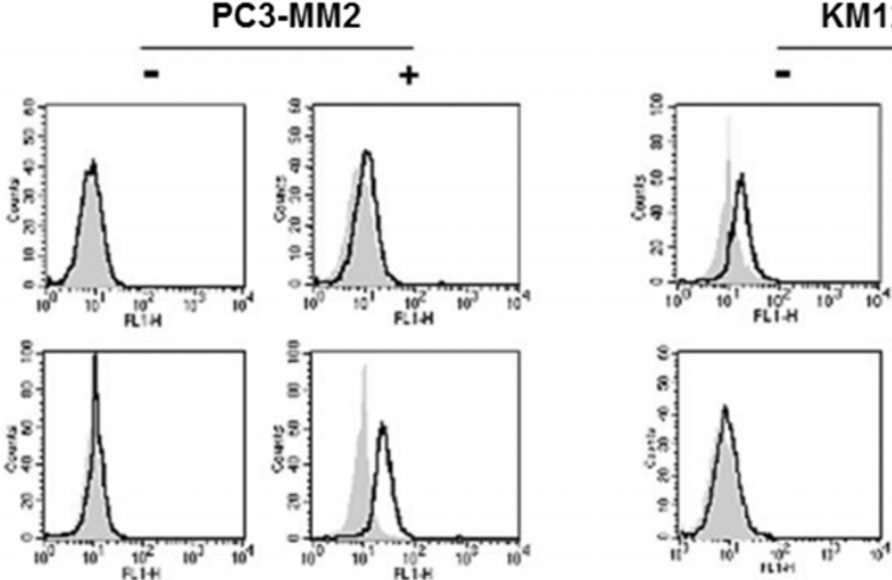

KM12L4A
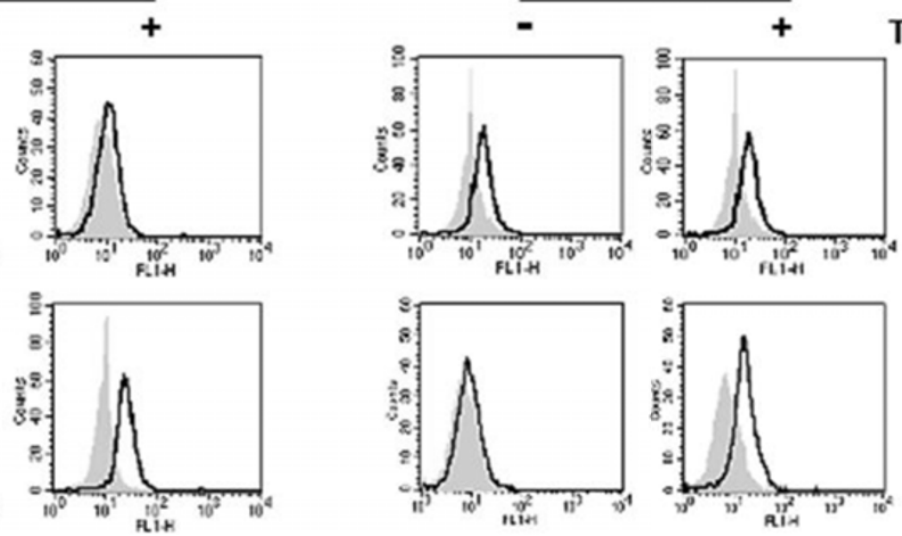

TRAIL

DR4

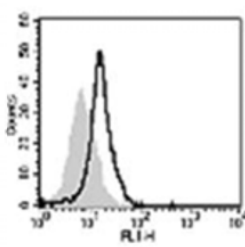

DR5

Figure 2 Effects of neutralizing antibodies to TRAIL receptors on TRAIL-induced apoptosis and expression of TRAIL receptors on the cell surface in PC3-MM2 and KM12L4A cells. (A) PC3-MM2 and KM12L4A cells were pretreated with the anti-DR4 or anti-DR5 antibodies (0.5 $\mu \mathrm{g} / \mathrm{ml}$ ) for $3 \mathrm{~h}$ and then PC3-MM2 and KM12L4A cells were treated with the indicated doses of TRAlL for 6 and 8 h, respectively. Goat lgG was used as the control isotype antibody. Apoptosis was detected by annexin $V$ binding assay. Each value represents the mean \pm SE of triplicate determinants. ${ }^{* *} p<0.001$. (B) PC3-MM2 and KM12L4A cells were treated with $2.5 \mathrm{ng} / \mathrm{ml}$ TRAlL for $3 \mathrm{~h}$. Thereafter, cells were stained with control mouse lgG or anti-DR4/DR5 antibody (1:100), and subsequently labeled with FITC-conjugated secondary antibodies (1:200) to determine the surface expression of DR4/DR5. The cell surface expression was measured by a flow cytometer. Shaded and unshaded peaks correspond to control and specific stainings, respectively.

MM2 and KM12L4A cells (Figure 3A). These changes in mRNA levels of c-FLIP $/$ s were followed by corresponding changes in their protein levels (Figure 3B). We also compared the expression level of myeloid cell leukemia sequence 1 (Mcl-1) protein between two pairs of primary and their highly metastatic cells, because Mcl-1 as well as c-FLIP is also the main determinant of acquired TRAIL resistance [17]. Like c-FLIP ${ }_{\mathrm{L} / \mathrm{S}}$, the basal level of
Mcl-1 was lower in highly metastatic PC3-MM2 and KM12L4A cells compared with their respective primary PC3 and KM12 cells, and the down-regulation of Mcl-1 by treatment with TRAIL was more sensitive in highly metastatic PC3-MM2 and KM12L4A cells compared with their respective primary $\mathrm{PC} 3$ and $\mathrm{KM} 12$ cells (Figure 3B). Therefore, our data indicated that high susceptibility to TRAIL of metastatic cancer cells is 


\section{A}
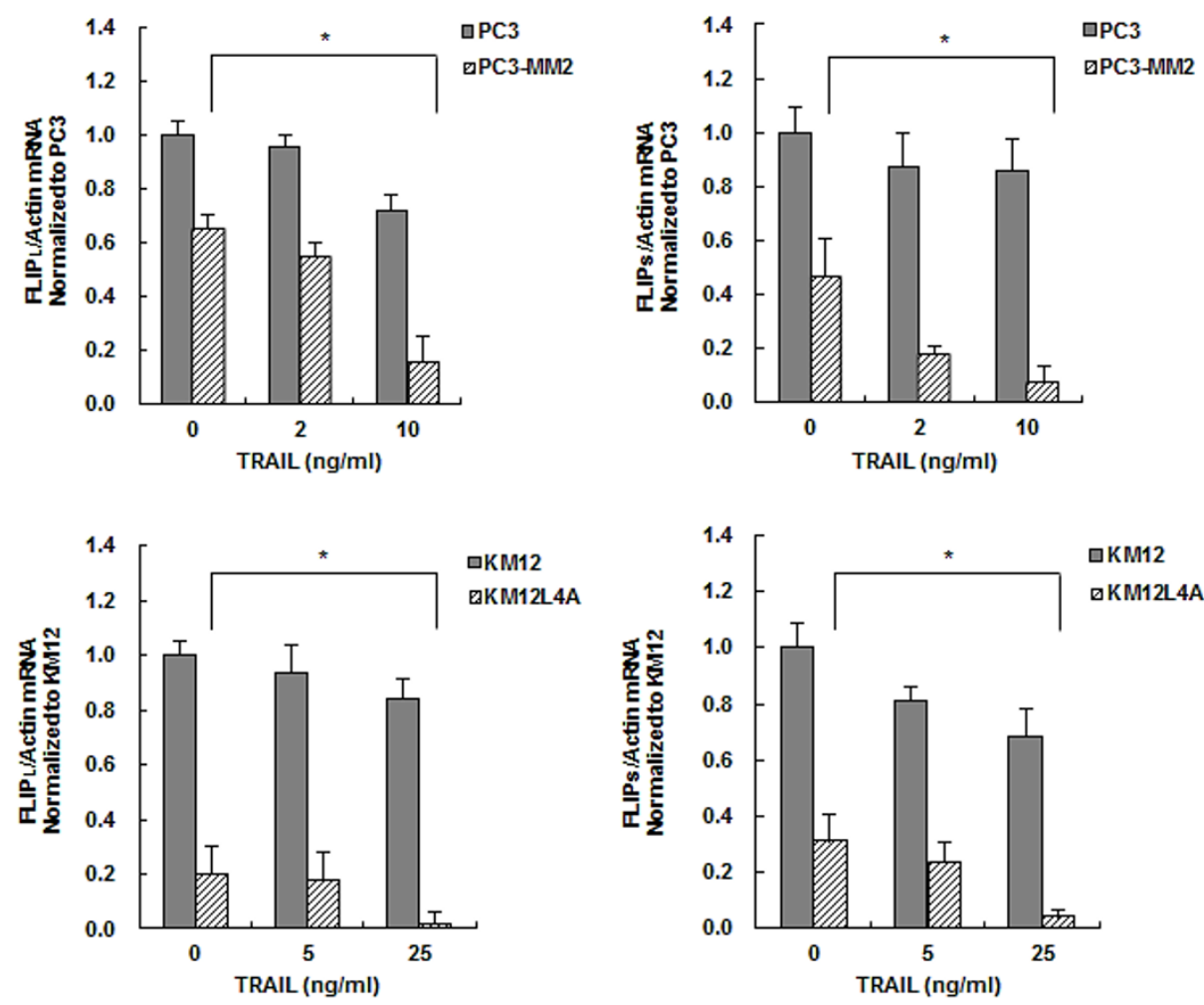

B
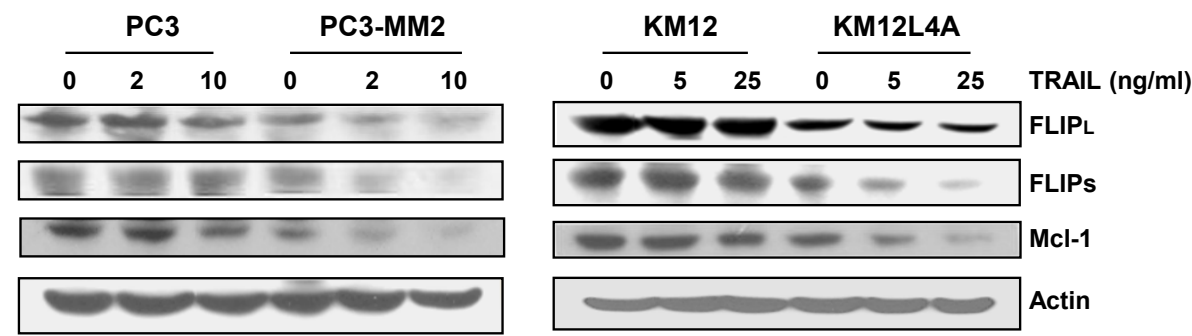

Figure 3 Down-regulation of c-FLIP $\mathrm{L}_{\mathrm{S}}$ and Mcl-1 in TRAIL-treated metastatic cancer cells. PC3 and PC3-MM2 cells were treated with 2 or $10 \mathrm{ng} / \mathrm{ml}$ TRAlL for $6 \mathrm{~h}$, and KM12 and KM12L4A cells were treated with 5 or $25 \mathrm{ng} / \mathrm{ml}$ TRAIL for $8 \mathrm{~h}$. After TRAlL treatment, the mRNA expression level of C-FLIPL/S (FLIPL/S) was measured by quantitative real-time RT-PCR (A), and protein levels of FLIPL/S and Mcl-1 were measured by Western blot analysis (B), respectively. $\beta$-Actin (Actin) was used as a loading control.

associated with up-regulation of DR5 and concurrent down-regulation of c-FLIP and Mcl-1 by TRAIL treatment.

Increased expression of c-Myc in metastatic cancer cells is associated with the increased susceptibility to TRAIL

It has been known that c-Myc renders cancer cells sensitive to TRAIL-induced apoptosis by the up-regulation of DR5, the activation of caspase-8, and the down-regulation of C-FLIP and Mcl-1 [13,18,19]. Since the metastatic PC3-MM2 cells showed the down-regulation of c-FLIP and Mcl-1, we determined the level of c-Myc expression in metastatic cancer cells. PC3-MM2 and KM12L4A cells showed significantly higher basal level of c-Myc than their primary PC3 and KM12 cells (Figure 4A). Since DNA-PK can phosphorylate c-Myc at several serine residues in vitro [20] and DNA-PKcs modulates the stability of c-Myc [15], we compared the level of DNA-PKcs between the primary and their cognate metastatic cancer cells. The level of DNA-PKcs was 
A

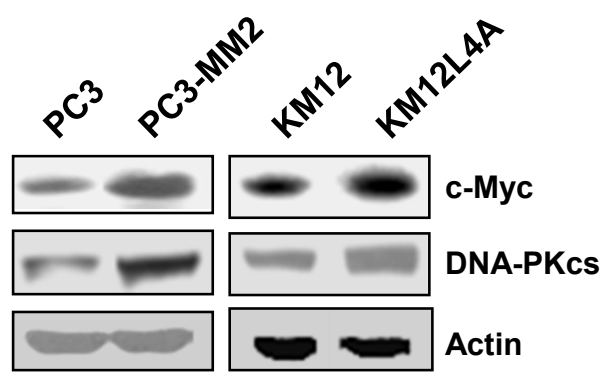

C

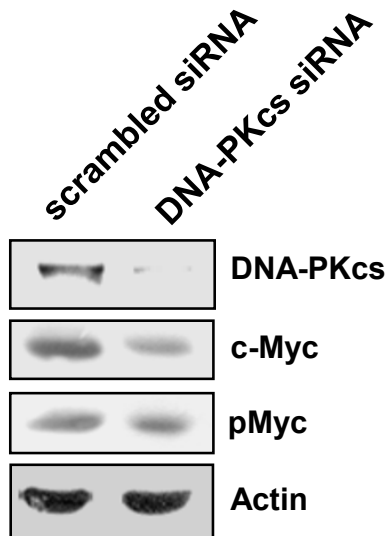

B

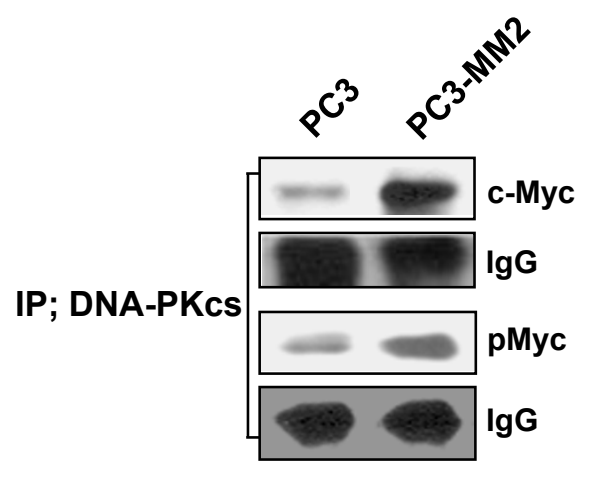

IP; c-Myc

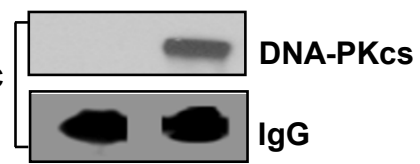

Figure 4 Over-expression of c-Myc and the cross-talk between DNA-PKcs and c-Myc in metastatic cancer cells. (A) The levels of c-Myc and DNA-PKCs proteins in PC3 and PC3-MM2 cells (left) and KM12 and KM12L4A cells (right) were determined using Western blot analysis. (B) Immunoprecipitates (IP) of the DNA-PKcs or c-Myc antibody from PC3 and PC3-MM2 cells were subjected to Western blot analysis with c-Myc, phospho-c-Myc (pMyc) or DNA-PKcs antibody to determine the interaction between DNA-PKcs and c-Myc. IgG was used as an internal control for the immunoprecipitation. (C) PC3 cells were transfected with siRNA against DNA-PKcs or scrambled siRNA as a control. After $48 \mathrm{~h}$, the cell lysates of the transfectants were subjected to Western blot analysis with c-Myc or pMyc antibody.

higher in metastatic PC3-MM2 and KM12L4A cells than in their primary cells (Figure 4A). These results were followed by the increased interaction between $\mathrm{C}$ Myc and DNA-PKcs in PC3-MM2 cells compared with PC3 cells in immunoprecipitation assay (Figure 4B) and the down-regulated levels of c-Myc and phospho-c-Myc (pMyc) after knock-down of DNA-PKcs with specific siRNA in PC3 cells (Figure 4C). These results suggest that the increased level of DNA-PKcs may be contributory to the over-expression of c-Myc protein in metastatic cancer cells.

To examine the effect of c-Myc on the sensitivity of the metastatic cells to TRAIL, PC3-MM2 cells were transfected with c-Myc siRNA or a scrambled siRNA. TRAIL-induced cell death was decreased by transfection of c-Myc siRNA in PC3-MM2 cells (Figure 5A). Moreover, siRNA against $c-M y c$ prevented the TRAIL- induced cell surface expression of DR5 (Figure 5B). Therefore, these results suggest that the increased level of c-Myc contributes to the hypersensitivity of metastatic cells to TRAIL, possibly in part due to TRAILinduced surface expression of DR5.

Activation of pro-caspases is accelerated after treatment with TRAIL in metastatic cancer cells over-expressing cMyc

c-Myc acts as a gatekeeper of the caspase feedback amplification loop and c-Myc-mediated priming of the mitochondrial pathway enables weak caspase- 8 signals to activate effector caspases and establish a death executing caspase feedback amplification loop [12]. Therefore, we determined if the increased susceptibility of metastatic cancer cells over-expressing c-Myc to TRAIL-induced apoptosis was accompanied by the 

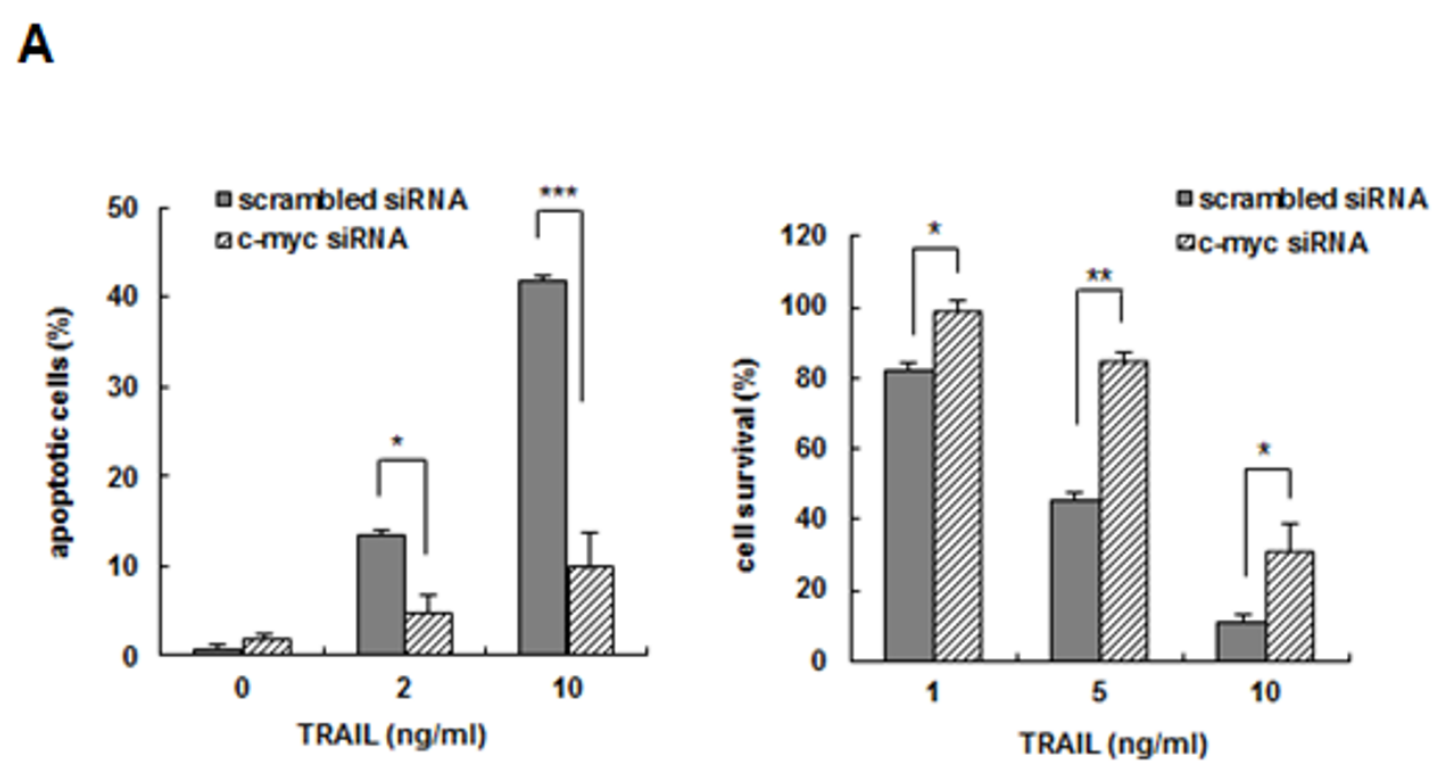

B

0
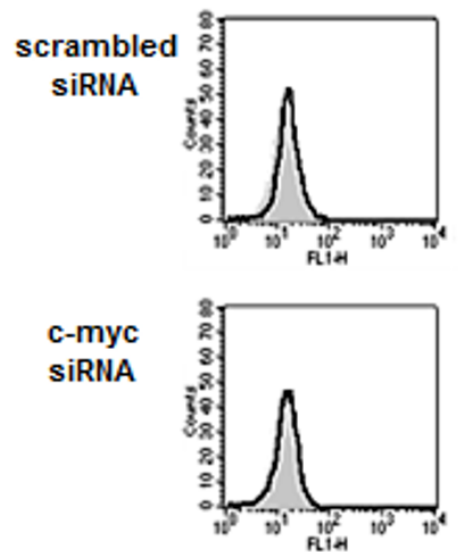

1
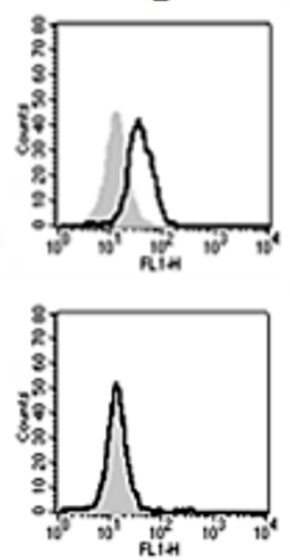

TRAIL (ng/ml)

a scrambled siRNA

c-myc siRNA

Figure 5 Targeted disruption of the c-Myc gene reduced the responsiveness to TRAIL and the expression of DR5 in PC3-MM2 cells. (A) PC3-MM2 cells were transfected with siRNA against c-Myc or scrambled siRNA as a control. After $48 \mathrm{~h}$, the transfectants were treated with TRAIL ( 2 or $10 \mathrm{ng} / \mathrm{ml}$ ) for $6 \mathrm{~h}$, and the percentage of apoptotic cells was determined using Annexin $V$ staining and flow cytometry (left). In addition, the transfectants were treated with graded single doses of TRAIL $(1 \sim 10 \mathrm{ng} / \mathrm{ml})$, and percentage of cell survival was determined after $96 \mathrm{~h}$ incubation using the MTT assay (right). Data represent the mean \pm SE of triplicate experiments. ${ }^{*} p<0.05,{ }^{* *} p<0.01$, ${ }^{* * *} p<0.001$. (B) The transfected cells incubated with anti-DR5 antibody (1:100), and subsequently labeled with FITC-conjugated secondary antibodies (1:200) to determine the surface expression of DR5. Mouse lgG was also used as an isotype control. The shaded and unshaded peaks correspond to control and specific staining, respectively.

increased activation of caspases (Figure 6A). Consistent with the hypersensitive response to TRAIL-induced cell death of metastatic cancer cells over-expressing c-Myc, the TRAIL-induced cleavage of procaspase-8, which is an initiator caspase linked to the receptor-mediated apoptotic pathway, was remarkably increased in the metastatic PC3-MM2 and KM12L4A cells as compared to the PC3 and KM12 cells, respectively. The proteolytic processing of caspase-9, which has been linked to the mitochondrial death pathway, was significantly induced in the metastatic cells following treatment of with TRAIL compared to their primary cells. In addition, the cleavage of procaspase- 3 , an executioner caspase, and PARP, a hallmark of caspase-3 activation, was 

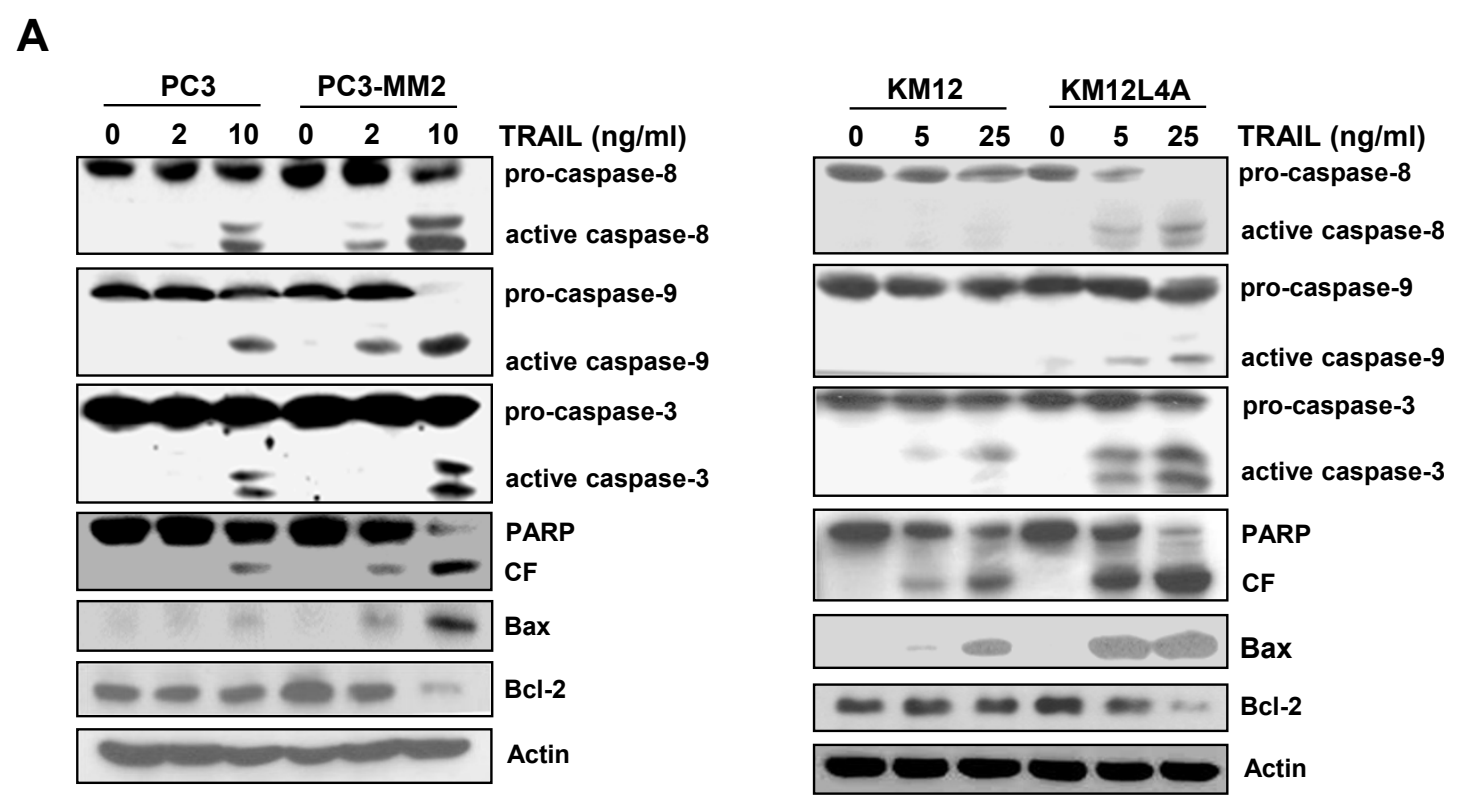

B

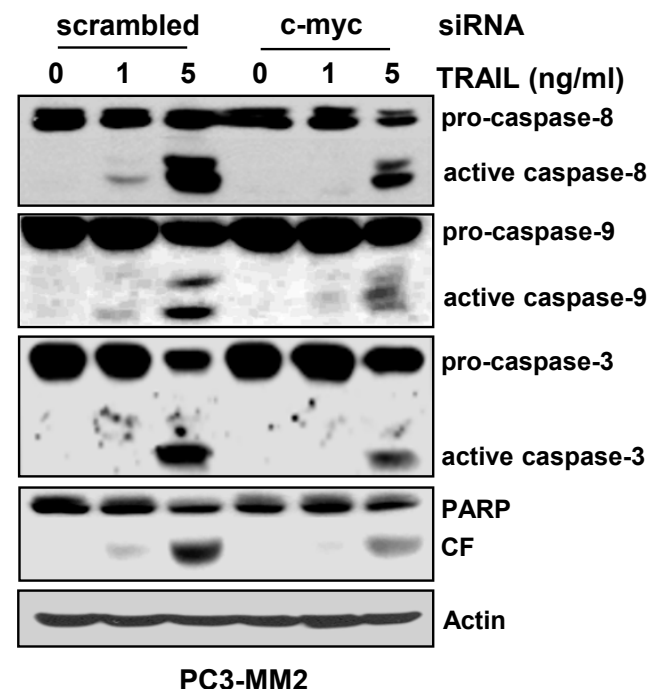

Figure 6 Increased activation of pro-caspases in TRAIL-treated metastatic cancer cells. (A) The cell lysates obtained from PC3 and PC3MM2 cells treated with 2 or $10 \mathrm{ng} / \mathrm{ml}$ TRAlL for $6 \mathrm{~h}$ (left) or KM12 and KM12L4A cells treated with 5 or $25 \mathrm{ng} / \mathrm{ml}$ TRAlL for $8 \mathrm{~h}$ (right) were subjected to Western blot analysis to monitor the levels of caspase-8, -9 and -3 , Bax and Bcl-2. The levels of PARP and its cleavage fragment (CF) in TRAlL-treated cells were also determined. (B) PC3-MM2 cells were transfected with siRNA against c-myc or scrambled siRNA as a control. After $48 \mathrm{~h}$, the transfectants were treated with TRAIL ( 1 or $5 \mathrm{ng} / \mathrm{ml}$ ) for $6 \mathrm{~h}$ and were subjected to Western blot analysis to monitor the change in activities of caspases and PARP. Actin was used as a loading control.

profoundly increased in metastatic cells compared with their primary counterparts. We also investigated whether the modulation of proapoptotic Bax and antiapoptotic Bcl-2 proteins was involved in the TRAILinduced apoptosis of the metastatic cells. The expression of $\mathrm{Bax}$ and $\mathrm{Bcl}-2$ was up-regulated and down-regulated following treatment with TRAIL, respectively, in the
PC3-MM2 and KM12L4A cells compared to their corresponding counterparts, consistent with the activation status of pro-caspase-9 in these cells. These results were followed by reduction of TRAIL-induced caspase activation and PARP cleavage by depletion of c-Myc with cMyc siRNA in PC3-MM2 cells (Figure 6B). Therefore, these data demonstrated that the high susceptibility of 
metastatic cells to TRAIL was at least in part due to the increased expression of c-Myc, suggesting that TRAIL effectively may induce caspase-dependent apoptosis in metastatic cells over-expressing c-Myc.

\section{The amplified TRAIL-induced caspase activation by overexpressed c-Myc counteract the anti-apoptotic activity of DNA-PKcs by increasing proteolytic cleavage in the metastatic cancer cells}

It has been known that a constitutively active Akt is an important regulator of TRAIL sensitivity [21,22], and inhibition of Akt activation by its pharmacological inhibitor or knockdown of its expression by siRNA sensitizes TRAIL-resistant cells to TRAIL $[23,24]$. The activation of Akt by phosphorylation of Ser-473 is mediated by DNA-PKcs [25]. However, the metastatic cancer cells were sensitive to TRAIL, despite that the metastatic cells have higher level of DNA-PKcs compared with their primary cells, as shown above. Therefore, we determined the levels of DNA-PKcs and pAkt in the metastatic cells after treatment with TRAIL (Figure 7A). In metastatic PC3-MM2 and KM12L4A cells, DNA-PKcs was cleaved and consequently the level of DNA-PKcs was decreased after exposure to TRAIL and this result was accompanied with decrease of pAkt level, whereas the levels of DNA-PKcs and pAkt were maintained in the primary PC3 and KM12 cells after exposure to TRAIL.

Since c-Myc could control the TRAIL sensitivity, and DNA-PKcs is a substrate of caspase-3 [26], we determined whether depletion of c-Myc could block degradation of DNA-PKcs. When PC3-MM2 cells were transfected with c-Myc siRNA, TRAIL-induced cleavage of DNA-PKcs was reduced compared with transfection with scrambled siRNA. These results were followed by prevention of cleavage of DNA-PKcs as well as PARP in the TRAIL-treated cells by pretreatment with Z-DEVDFMK, a caspase-3-specific inhibitor (Figure 7B). These results suggest that the amplified TRAIL-induced caspase activation by over-expressed c-Myc may curtail the anti-apoptotic activity of DNA-PKcs by increasing its proteolytic cleavage in the metastatic cancer cells.

\section{Suppression of DNA-PKcs is associated with hypersensitivity to TRAIL-induced cytotoxicity}

To investigate the direct role of DNA-PKcs in the susceptibility of the metastatic cells to TRAIL, we used siRNA to knockdown DNA-PKcs expression and determined its effect on TRAIL sensitivity. After transfection of PC3 or KM12 cells with siRNA against DNA-PKcs or scrambled siRNA, the expression of DNA-PKcs was efficiently suppressed by DNA-PKcs siRNA as compared to the control cells and its expression was further decreased by TRAIL treatment (Figure $8 \mathrm{~A}$ ). This result was followed by the hypersensitivity to TRAIL-induced reduction of DNA-PKcs/pAkt levels, activation of caspases, PARP cleavage, and up-regulation of Bax in PC3 and KM12 cells after transfection with DNA-PKcs siRNA as compared to the cells transfected with scrambled siRNA. Furthermore, the knockdown of DNA-PKcs with specific siRNA significantly increased TRAIL-induced apoptosis in PC3 and KM12 cells (Figure 8B).

Since knockdown of c-Myc suppressed the TRAILinduced cleavage of DNA-PKcs and knockdown of DNA-PKcs increased TRAIL-induced activation of caspases, c-Myc overexpressed in the metastatic cancers may increase TRAIL-induced cleavage of DNA-PKcs and consequently caspase-mediated apoptosis. We then determined whether the knockdown of DNA-PKcs leads to the enhancement of TRAIL sensitivity via the up-regulation of the cell surface expression of death receptors. The suppression of DNA-PKcs with specific siRNA in the PC3 and KM12 cells resulted in an increase in the cell surface expression of DR5 (Figure 9A), but not DR4 (data not shown), and this up-regulation was increased further by TRAIL treatment. Moreover, we also showed that the cell surface expression of DR5 in PC3 and KM12 cells was induced by treatment with 4,5dimethoxy-2-nitrobenzaldehyde (DMNB) [27], a specific inhibitor of DNA-PK (Figure 9B). These results indicate that the inhibition of the DNA-PKcs/Akt signaling pathway may contribute to the sensitization of PC3 or KM12 cells to TRAIL-induced apoptosis through the up-regulation of DR5 cell surface expression and the activation of caspase cascade.

\section{Combination of DMNB and TRAIL renders PC3 and KM12 cells highly susceptible to TRAIL-induced apoptosis}

Since the suppression of DNA-PKcs level with siRNA induced the up-regulation of DR5 and the activation of caspases, we determined whether DMNB could potentiate TRAIL-induced cytotoxicity and apoptosis in TRAIL-resistant PC3 and KM12 cells and function as a TRAIL sensitizer. DMNB in combination with TRAIL sensitized PC3 cells (Figure 10A) and KM12 cells (Figure 10B) to TRAIL-induced cytotoxicity and apoptosis in a dose-dependent manner. We next examined whether the enhanced susceptibility of PC3 and KM12 cells to TRAIL following DMNB treatment was associated with caspase activation and the up-regulation of Bax through the inactivation of the DNA-PKcs/Akt signaling (Figure 11A). Co-treatment of PC3 or KM12 cells with TRAIL and DMNB resulted in a decrease in the levels of both DNA-PKcs and pAkt when compared to cells treated with TRAIL alone. The combination of DMNB and TRAIL was more effective for the activation of caspases, the inactivation of the DNA-PKcs/Akt signaling pathway, PARP cleavage, and the up-regulation of 
A
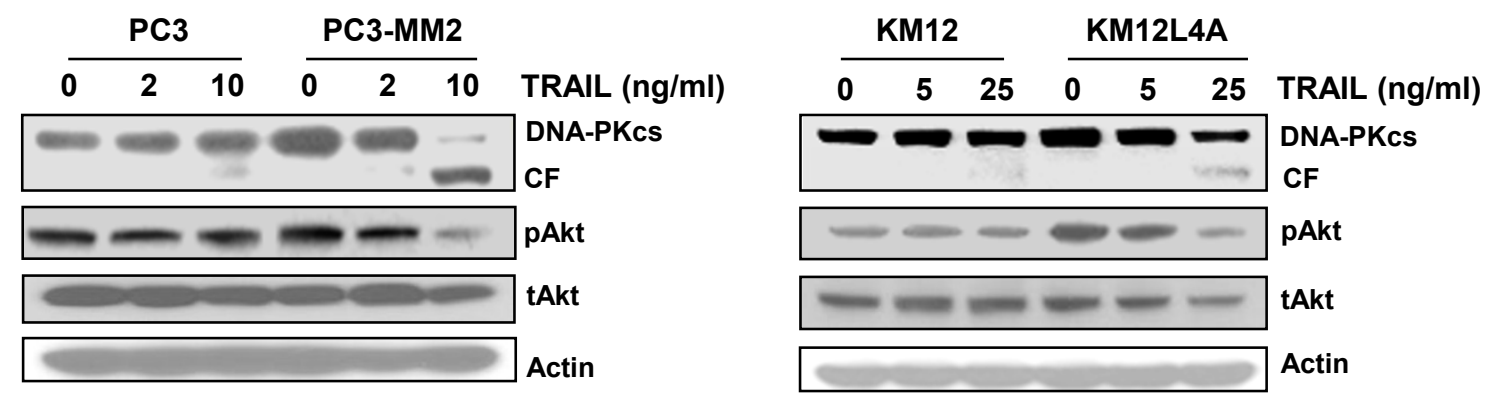

B
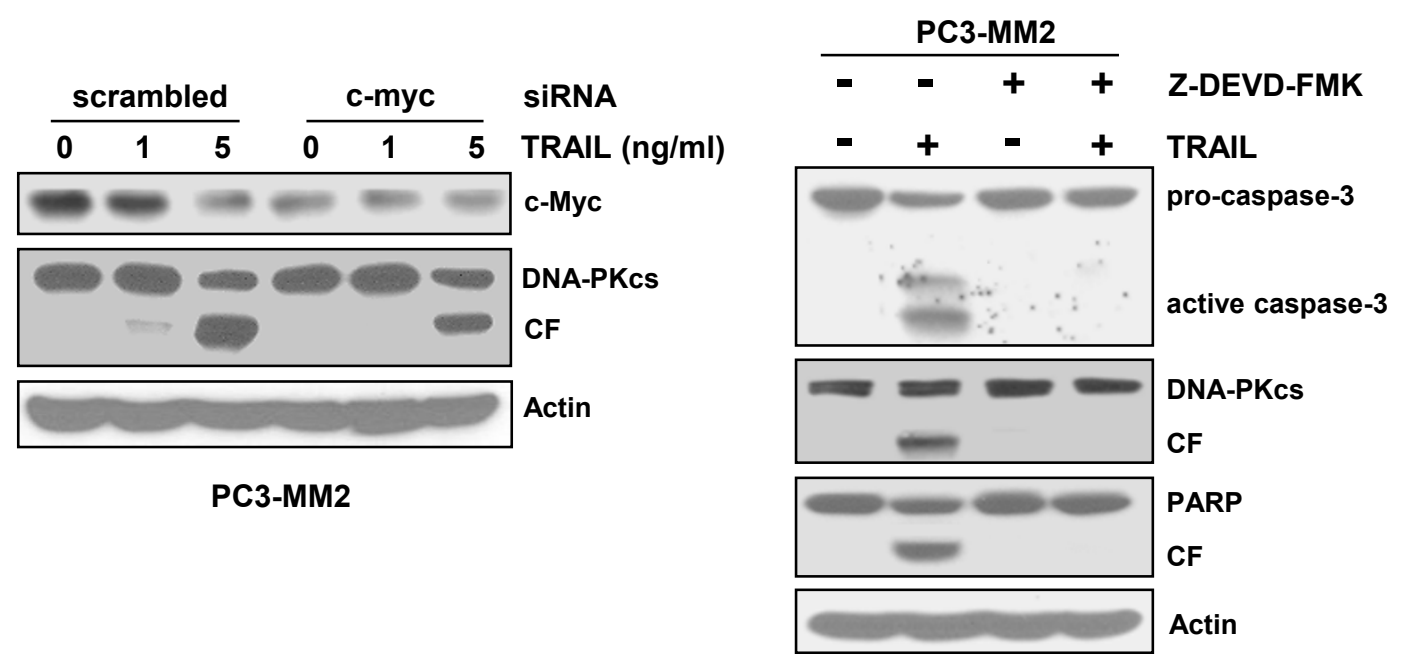

Figure 7 Down-regulation of DNA-PKcs/pAkt in TRAIL-treated metastatic cancer cells and prevention of caspase-3 dependent DNAPKcs cleavage by suppression of c-Myc in the cells. (A) The cell lysates obtained from PC3 and PC3-MM2 cells (left) treated with TRAIL (2 or $10 \mathrm{ng} / \mathrm{ml}$ for $6 \mathrm{~h}$ ) or KM12 and KM12L4A cells (right) treated with TRAIL (5 or $25 \mathrm{ng} / \mathrm{ml}$ for $8 \mathrm{~h}$ ) were subjected to Western blot analysis to monitor the levels of DNA-PKcs and its CF, phosphorylated Akt Ser473 (pAkt) and total Akt (tAkt). Actin was used as a loading control. (B) PC3MM2 cells were transfected with siRNA against c-myc or scrambled siRNA as a control. After $48 \mathrm{~h}$, the transfectants were treated with TRAlL (1 or $5 \mathrm{ng} / \mathrm{ml}$ ) for $6 \mathrm{~h}$ and were subjected to Western blot analysis to monitor the changed levels of c-Myc and DNA-PKcs (left). The cell lysates of PC3-MM2 cells treated with TRAIL $(5 \mathrm{ng} / \mathrm{ml}$ ) for $4 \mathrm{~h}$ were subjected to Western blot analysis to monitor levels of caspase-3, DNA-PKcs, PARP and their CFs. Some samples were pretreated with $50 \mu \mathrm{M}$ Z-DEVD-FMK, a specific caspase-3 inhibitor, for $2 \mathrm{~h}$ (right).

Bax than the treatment with TRAIL alone. In addition, combined treatment of DMNB and TRAIL increased surface expression of DR5 in both PC3 and KM12 cells, which did not respond to TRAIL alone (Figure 11B). These results suggest that the inactivation of the DNAPKcs/Akt signaling pathway with siRNA or small molecules may be a useful strategy to increase the susceptibility of TRAIL-resistant solid tumor cells to TRAILinduced cell death.

\section{Discussion}

It is unclear why some cells are sensitive to TRAILinduced apoptotic stimuli, whereas other cell types survive after exposure to TRAIL. Therefore, it is necessary to characterize the molecular mechanisms underlying this apoptotic sensitivity. Furthermore, the molecular determinants regulating TRAIL sensitivity in metastatic cancer cells are still poorly understood. In this study, we demonstrated the differential TRAIL responsiveness of primary human prostate adenocarcinoma PC3 and colorectal carcinoma KM12 cells and their respective highly metastatic $\mathrm{PC} 3-\mathrm{MM} 2$ and KM12L4A sublines. Interestingly, PC3-MM2 and KM12L4A cells were more susceptible to TRAIL than their primary counterparts. We found that DR5 could be the major receptor involved in TRAIL-mediated 
A

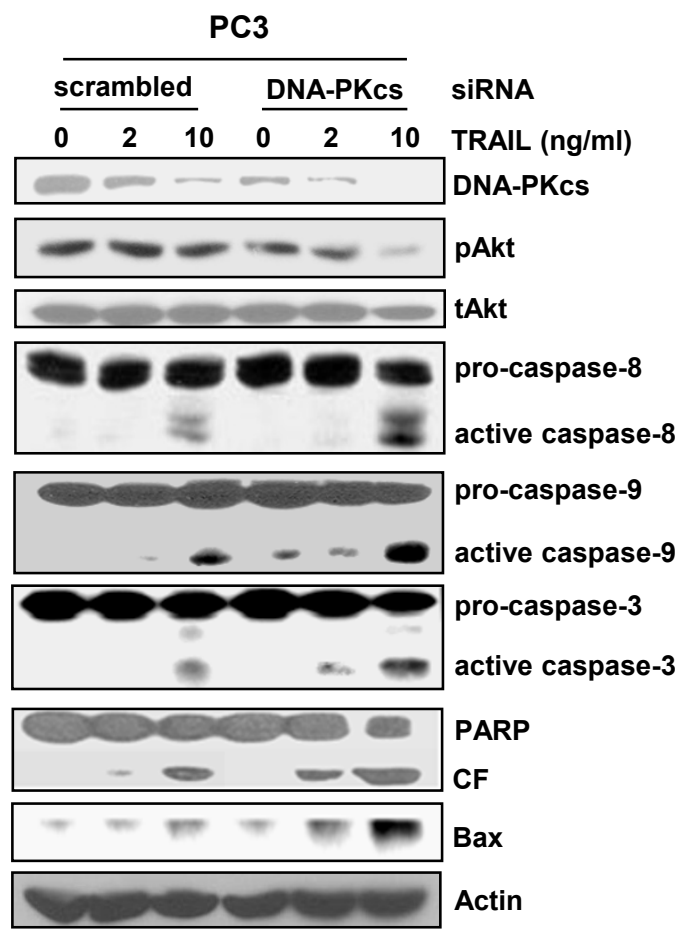

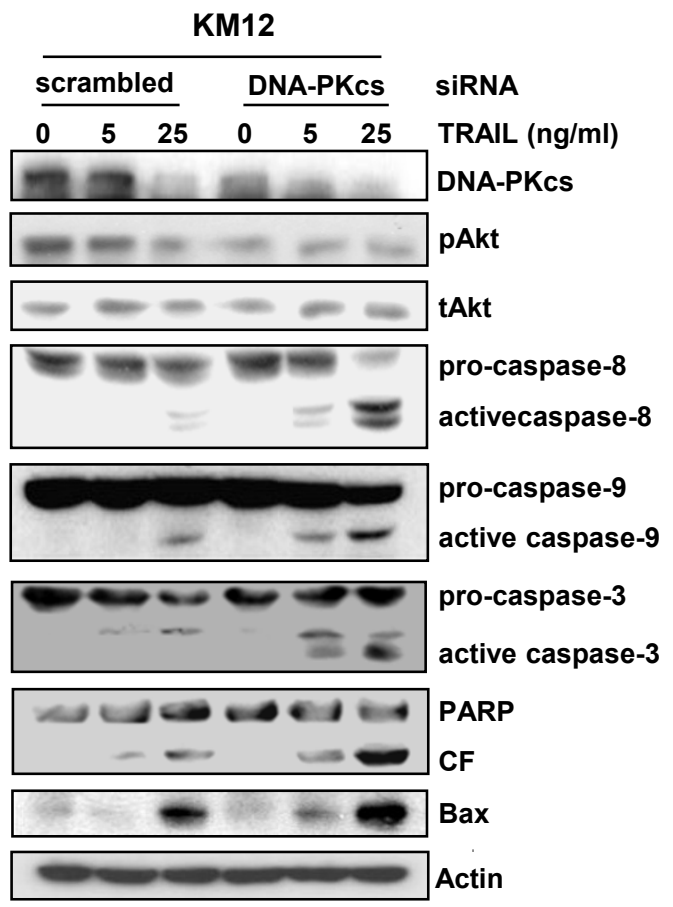

B

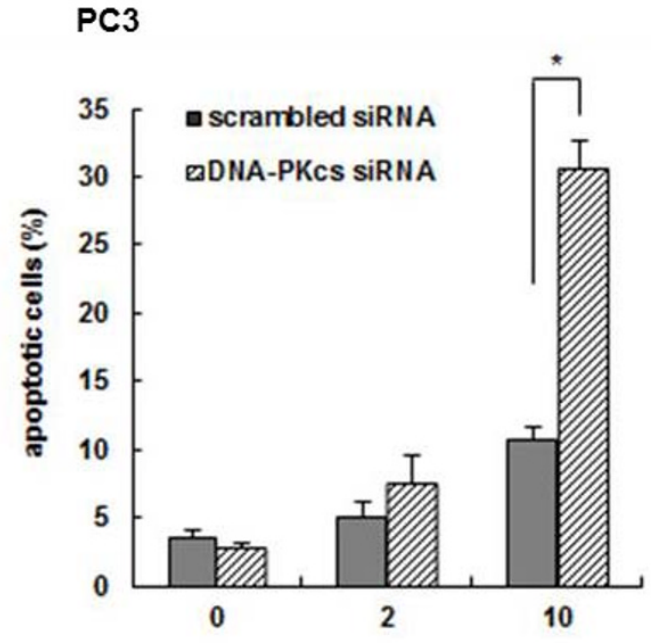

TRAIL (ng/ml)
KM12

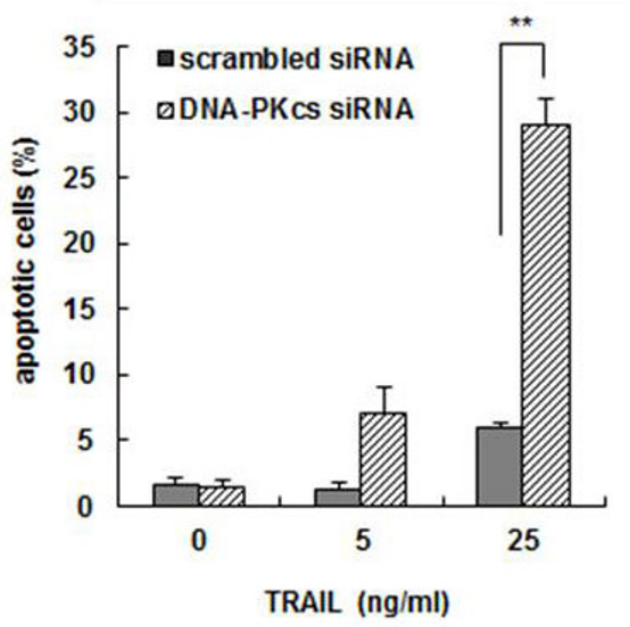

Figure 8 Suppression of DNA-PKcs leads to activation of caspase and Bax through the inactivation of the DNA-PKcs/Akt signaling pathway and enhances responsiveness to TRAIL. (A) PC3 (left) and KM12 cells (right) were transfected with siRNA against DNA-PKcs or scrambled siRNA as a control. After $48 \mathrm{~h}$, the transfected PC3 and KM12 cells treated with the indicated doses of TRAIL for 6 and 8 h, respectively, and were subjected to Western blot analysis to monitor the levels of DNA-PKcs, pAkt, tAkt, caspases (caspase-8, -9, and -3) and Bax. The levels of PARP and its cleavage fragment (CF) in the transfectants were also determined. Actin was used as a loading control. (B) PC3 (left) and KM12 cells (right) were transfected with siRNA against DNA-PKcs or scrambled siRNA as a control. After 48 h, the transfected cells were treated with the indicated doses of TRAIL for 6 and $8 \mathrm{~h}$, respectively. Thereafter, the percentage of apoptotic cells was determined using Annexin $\vee$ staining and flow cytometry (right). Each value represents the mean \pm SE of triplicate determinants. ${ }^{*} p<0.05,{ }^{*} p<0.01$. 


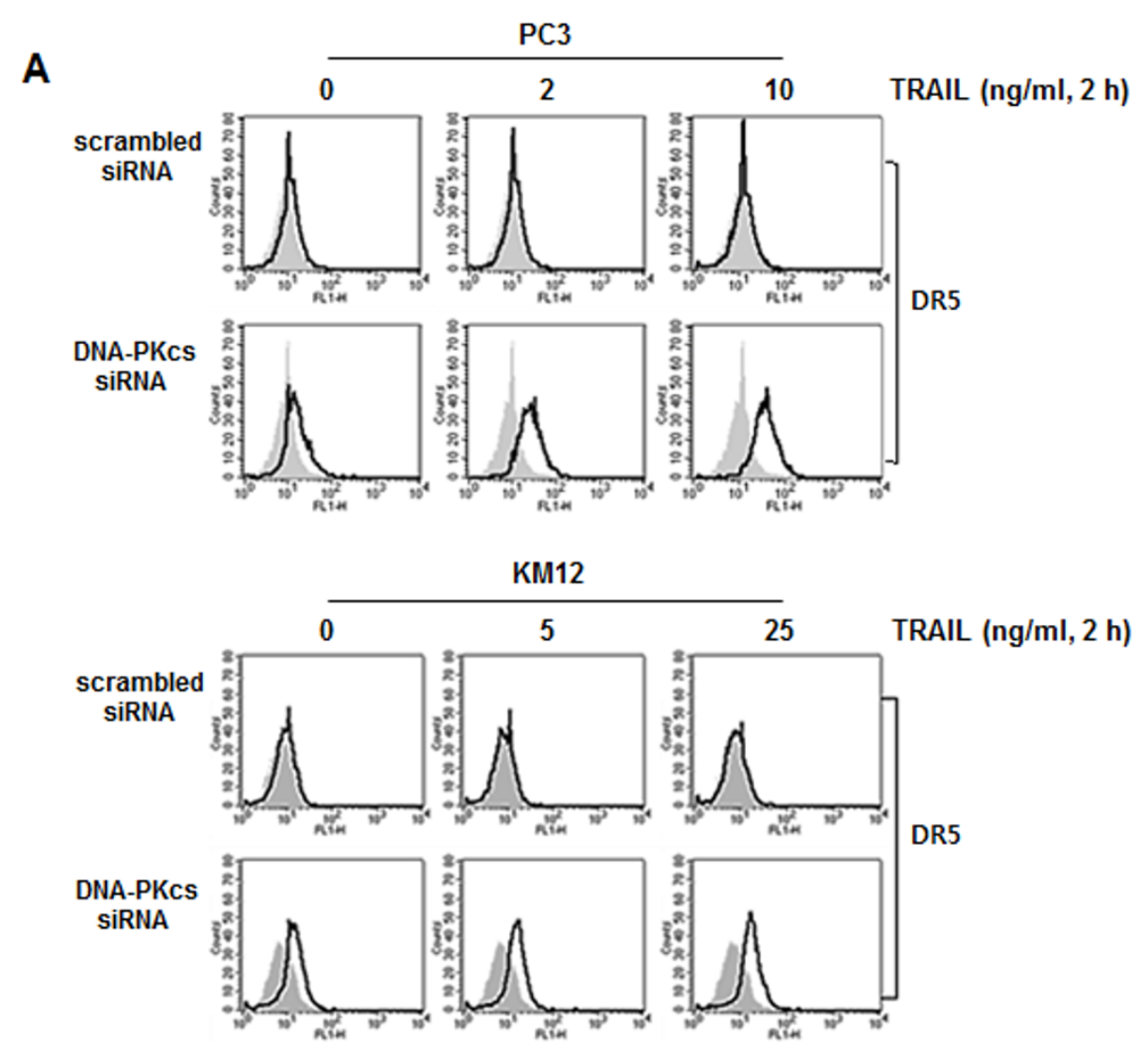

B
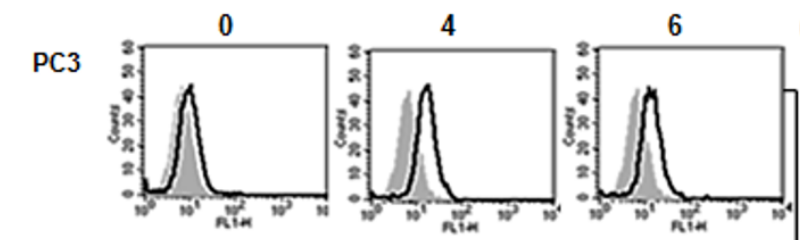

(h, $5 \mu$ M DMNB )

KM12
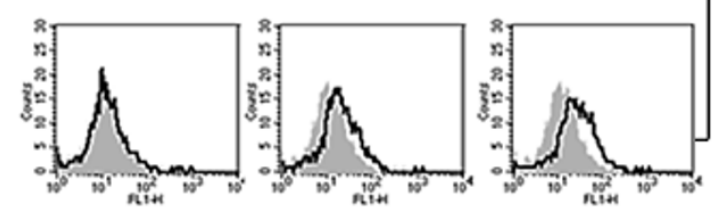

DR5

Figure 9 Suppression of DNA-PKcs leads to an increase of cell surface expression of DR5. (A) PC3 and KM12 cells were transfected with siRNA against DNA-PKcs or scrambled siRNA as a control. After $48 \mathrm{~h}$, the transfected cells were treated with the indicated doses of TRAlL for 2 h. Thereafter, the transfected cells were incubated with anti-DR5 antibody (1:100), and subsequently labeled with FITC-conjugated secondary antibodies (1:200) to determine the surface expression of DR5. (B) PC3 (upper) and KM12 cells (lower) were treated with $5 \mu$ M DMNB for 4 and 6 $\mathrm{h}$, and then incubated with an anti-DR5 antibody (1:100), and subsequently labeled with FITC-conjugated secondary antibodies (1:200) to determine the surface expression of DR5. Mouse lgG was used as an isotype control. The shaded and unshaded peaks correspond to control and specific staining, respectively.

apoptosis of these highly metastatic cells. Previously, we and other group reported that the expression of DR5 in MDR cells was up-regulated following TRAIL treatment $[28,29]$. In case of our results, cell surface expression of DR5, but not DR4, in PC3-MM2 and KM12L4A cells was up-regulated after TRAIL treatment whereas DR4/ DR5 expression in primary PC3 and KM12 cells was not modulated by TRAIL treatment (data not shown).
Moreover, pre-treating PC3-MM2 and KM12L4A cells with a neutralizing antibody against the DR5 receptor strongly reduced the degree of apoptosis induced by TRAIL. However, DR4 neutralizing antibody did not significantly affect TRAIL-triggered apoptosis in these highly metastatic cells, indicating that TRAIL induced apoptosis occurs preferentially via DR5, and therefore, DR5 could be the major receptor involved in increased 


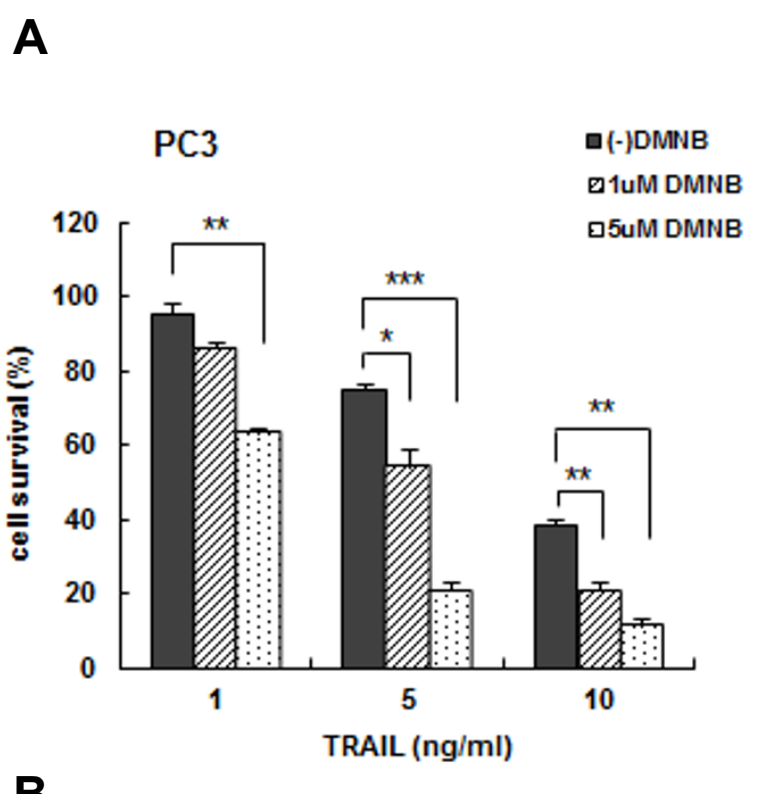

B
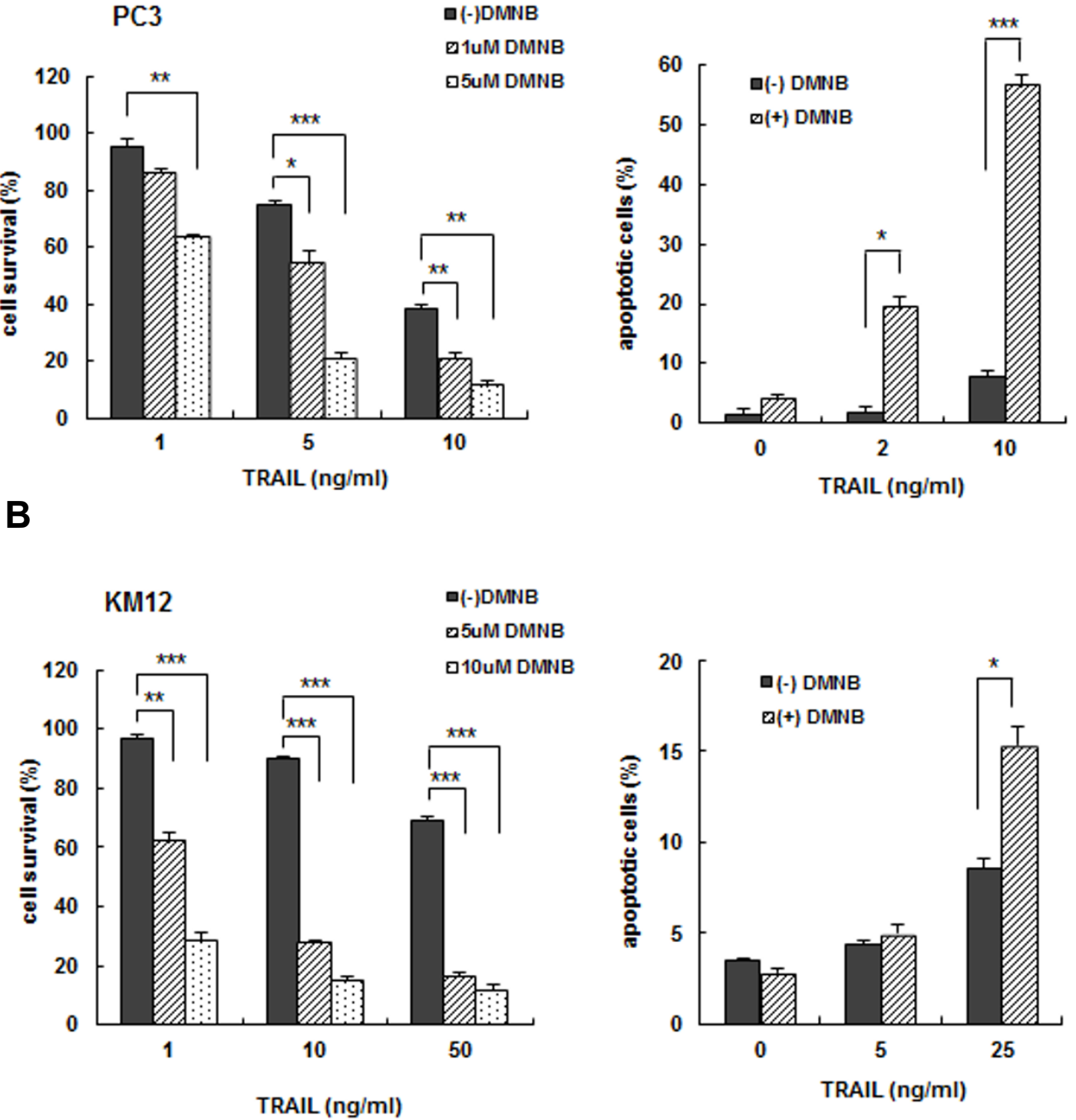

Figure 10 Effect of DMNB on TRAIL-induced cytotoxicity and apoptosis. PC3 (A) and KM12 (B) cells were treated with the indicated doses of TRAIL in the presence or absence of DMNB $(1,5$, or $10 \mu \mathrm{M})$, and cell survival was determined after $96 \mathrm{~h}$ of incubation using the MTT assay (left). PC3 and KM12 cells were treated with the indicated doses of TRAlL in the presence or absence of $5 \mu \mathrm{M}$ DMNB for 6 or 8 h, respectively. Thereafter, the percentage of apoptotic cells was determined using Annexin $V$ staining and flow cytometry (right). Each point is the average of triplicate determinants. ${ }^{*} p<0.05,{ }^{* *} p<0.01,{ }^{* * *} p<0.001$.

susceptibility of metastatic cells to TRAIL. We also found that the levels of c-FLIP $\mathrm{L}_{\mathrm{S}}$ and Mcl-1, the major factors for resistance to TRAIL-induced apoptosis, were significantly decreased in PC3-MM2 and KM12L4A cells compared to their primary counterparts. Therefore, our data suggest that high susceptibility to TRAIL of metastatic cancer cells is associated with up-regulation of DR5 and concurrent down-regulation of c-FLIP $\mathrm{L}_{\mathrm{S}}$ and Mcl-1.
It has been reported that TRAIL-resistant cells can be resensitized by c-Myc, which induces DR5 expression, and represses the transcription of both c-FLIP and Mcl-1 [30]. Consistently, in our data the expression of c-Myc was significantly increased in PC3-MM2 and KM12L4A cells with high metastatic potency compared to their primary cells. c-Myc is deregulated in a wide range of human cancers, including breast, colon, cervical and small-cell lung carcinomas, osteosarcomas, glioblastomas, melanoma and 


\section{A}
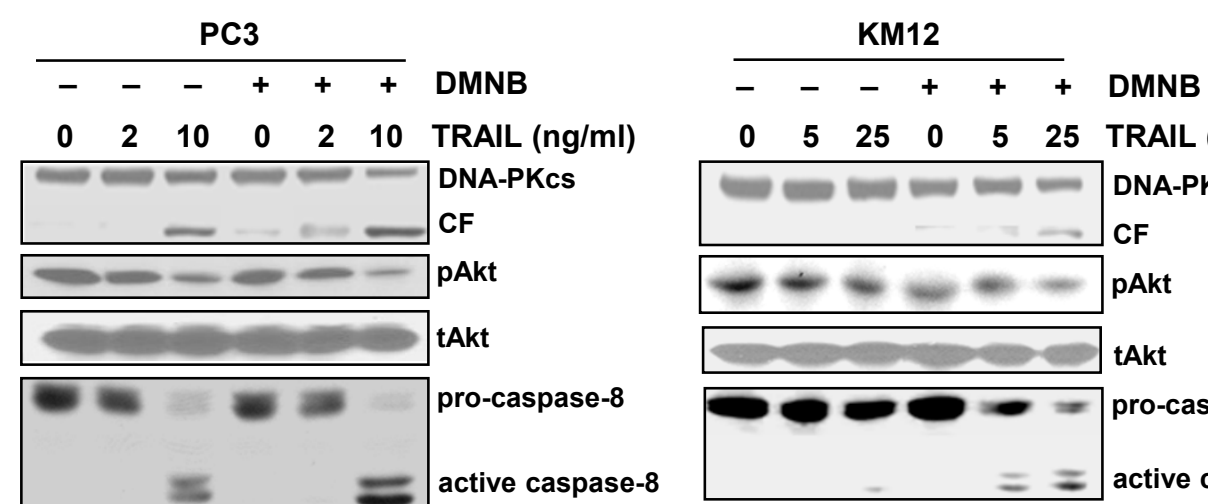

$$
\begin{array}{lllllll}
0 & 5 & 25 & 0 & 5 & 25 & \text { TRAlL }(\mathrm{ng} / \mathrm{ml})
\end{array}
$$
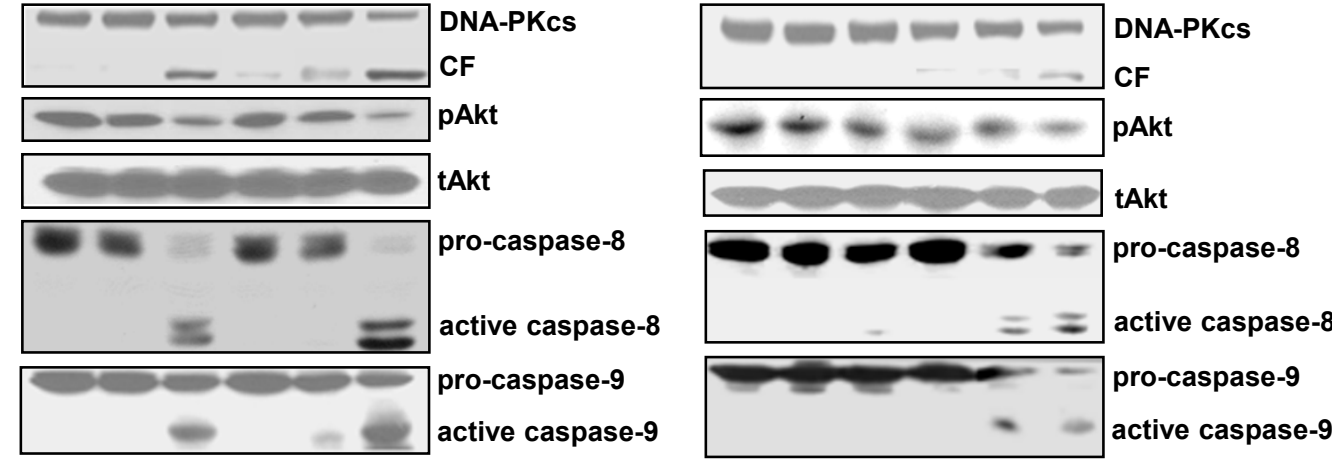

pro-caspase-9
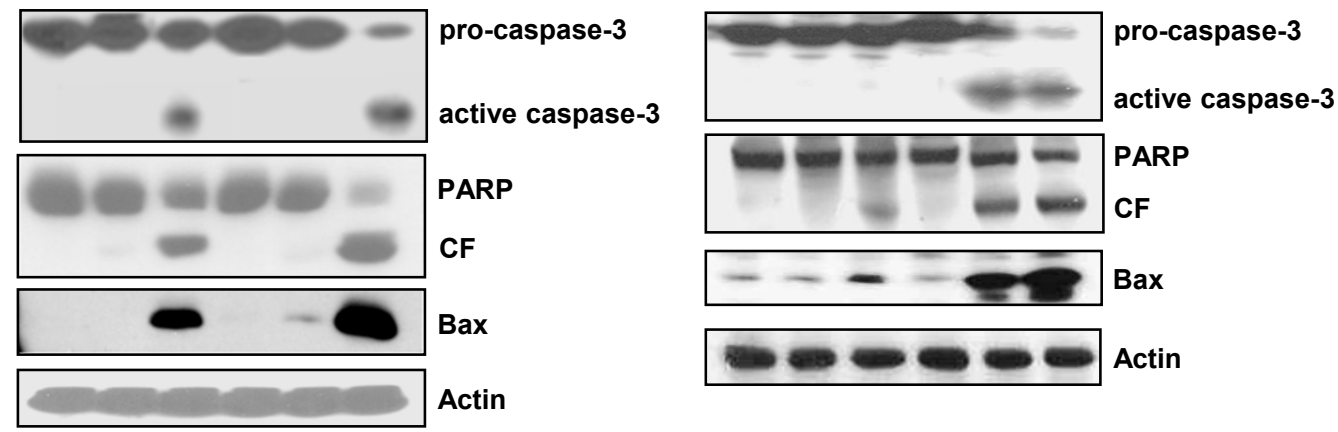

B

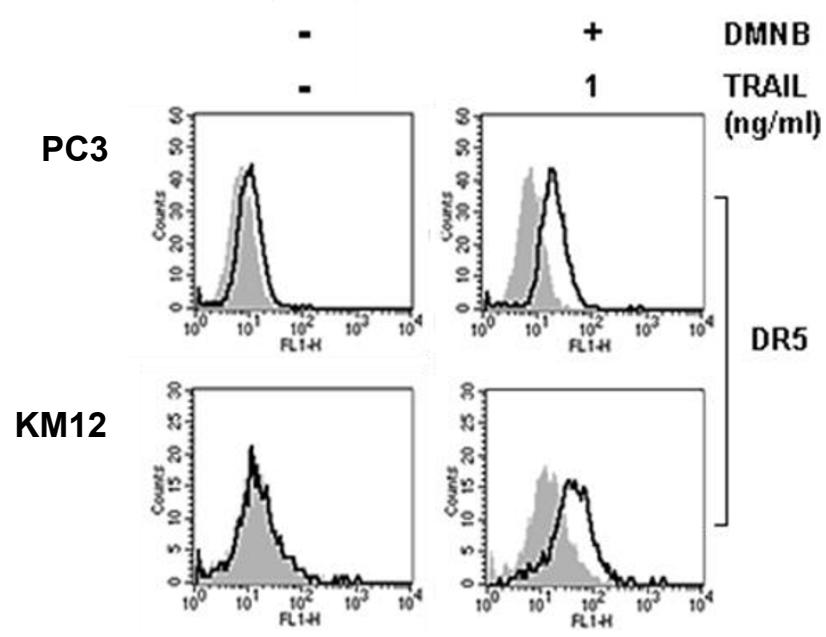

Figure 11 Combination effects of DMNB and TRAIL on DNA-PKcs/Akt molecules and caspase activity. (A) PC3 cells (left) and KM12 cells (right) were treated with the indicated doses of TRAlL in the presence or absence of $5 \mu \mathrm{M}$ DMNB for 6 or $8 \mathrm{~h}$, respectively, and assessed using Western blot analysis to monitor the protein levels of DNA-PKCs, pAkt and tAkt. The activation of caspases and Bax and the cleavage of PARP in cells treated with TRAlL and/or DMNB were determined by Western blot analysis. Actin was used as a loading control. (B) PC3 and KM12 cells were treated with $1 \mathrm{ng} / \mathrm{ml}$ TRAIL in the presence or absence of $5 \mu \mathrm{M}$ DMNB for $2 \mathrm{~h}$, and then incubated with an anti-DR5 antibody (1:100), and subsequently labeled with FITC-conjugated secondary antibodies (1:200) to determine the surface expression of DR5. Mouse IgG was used as an isotype control. The shaded and unshaded peaks correspond to control and specific staining, respectively. 
myeloid leukaemias, and c-Myc over-expression is frequently correlated with aggressive metastasis, poor differentiation and poor prognosis [31]. Paradoxically, in addition to promoting proliferation, c-Myc inhibits survival signals, resulting in apoptosis, if the apoptotic signal is sufficiently strong [11]. On the other hand, activation of c-Myc renders primary and non-transformed cells sensitive to TNF- $\alpha$, CD95L, and TRAIL-induced apoptosis $[13,18,19,32,33]$. It is known that c-Myc can alter the expression of several key players of the death receptor pathway, such as up-regulation of DR5 [13] and downregulation of c-FLIP [19], promoting the activation of death receptors and DISC and, thus, renders cells sensitive to TRAIL-induced apoptosis [31]. In addition, it was demonstrated that c-Myc suppresses $\mathrm{Mcl}-1$ transcription, and is constitutively bound to the $M c l-1$ promoter [18]. Therefore, our results suggest that increased sensitivity to TRAIL in metastatic cancer cells may be in part due to increased expression of c-Myc in the cells, which is associated with up-regulation of DR5 cell surface expression and down-regulation of c-FLIP and Mcl-1. In addition to enhancement of death-receptor signaling, c-Myc also amplifies the death signal at the mitochondria for synergistic induction of apoptosis by activating Bak, enabling TRAIL to fully activate the caspase machinery in human cells $[10,12]$. We found that after treatment with TRAIL activity of caspases including caspase- $8,-9$, and -3 were higher, and up-regulation of Bax and down-regulation of Bcl-2 were more significant in PC3-MM2 and KM12L4A cells than in their primary cells. Since c-FLIP $\mathrm{L}_{\mathrm{L}}$ and Mcl-1 were known as substrates of caspases [34,35], it could be possible that TRAIL-induced potent activation of caspases in metastatic cancer cells led to accelerated downregulation of $\mathrm{c}-\mathrm{FLIP}_{\mathrm{L}}$ and $\mathrm{Mcl}-1$. Therefore, these increased proapoptotic responses to TRAIL in the highly metastatic cancer cells might be attributed to the increased level of c-Myc.

Moreover, PC3-MM2 and KM12L4A cells showed the enhanced constitutive expression of DNA-PKcs as well as c-Myc compared to the corresponding primary cells. DNA-PK, a complex consisting of the regulatory subunits Ku70/80 and the catalytic subunit DNA-PKcs, plays a central role in the repair of DNA double-strand breaks (DSB). Over-expression of DNA-PKcs was reported in various human tumors [36-38], and the activity and protein/mRNA levels of DNA-PKcs were significantly higher in tumor tissues than in normal tissues [39]. Previously we demonstrated that the DNA-PK activity is remarkably increased in metastatic cancer cells [14]. Although DNA-PKcs was primarily defined as a component of the DNA DSB repair complex, DNA-PKcs is implicated, directly and indirectly, in various cellular metabolic processes, since DNA-PKcs may be able to phosphorylate the oncoproteins $\mathrm{c}-\mathrm{Myc}, \mathrm{c}-\mathrm{fos}$, and c-abl
[40]. DNA-PKcs activity may contribute to the overexpression of c-Myc, probably via its critical role in maintaining the stability of c-Myc $[15,40]$. DNA-PKcs also activates Akt via phosphorylation of Ser473, which in turn inactivates GSK-3 $\beta$ via phosphorylation of Ser9, resulting in the stabilization of c-Myc [15]. We showed a prominent interaction between DNA-PKcs and c-Myc and an increased level of phosphorylated c-Myc levels in PC3-MM2 cells compared to PC3 cells, suggesting the possibility that the overexpressed DNA-PKcs might contribute to the overexpression c-Myc in metastatic cancer cells via its stabilization. As previously described, c-Myc can participate in cell death as a pro-apoptotic factor $[10,12]$. In our experiment, we demonstrated that siRNA-mediated depletion of c-Myc in metastatic cancer cells suppressed TRAIL-induced up-regulation of DR5 and activation of caspase, and these phenomena could be associated with decreased cytotoxic effect of TRAIL on PC3-MM2 and KM12L4A cells.

It is known that the inhibition of Akt in gliomas enhances their susceptibility to TRAIL [41] and TRAIL down-regulates Akt levels by caspase-dependent degradation [42]. In addition, DNA-PKcs, an upstream regulator of Akt, is cleaved by caspase- 3 and, thus, the inactivation of these molecules occurs during apoptosis $[43,44]$. Our data showed that the cleavage of DNAPKcs and the subsequent reduction of DNA-PKcs and pAkt levels occurred in the PC3-MM2 and KM12L4A cells after TRAIL treatment, but not in their primary counterparts, even though the metastatic cells exhibited higher basal levels of DNA-PKcs and pAkt than their primary counterparts. This TRAIL-induced suppression of DNA-PKcs/Akt signaling pathway in metastatic cancer cells seemed to be at least in part due to overexpression of c-Myc, since it was prevented by knockdown of c-Myc. Therefore, our results suggest that the amplified TRAIL-induced caspase activation by overexpressed cMyc may suppress the anti-apoptotic activity of DNAPKcs by increasing its proteolytic cleavage and consequently promote apoptosis in the metastatic cancer cells. Finally, we found that suppression of DNA-PKcs by siRNA and DNMB significantly increased TRAILinduced growth inhibition and apoptosis in TRAILinsensitive PC3 or KM12 cells, which was accompanied by the inhibition of Akt S473 phosphorylation, the activation of caspases (caspase-8, -9, and -3), and the upregulation of the cell surface expression of DR5. Indeed, it has been reported that inhibitors of DNA-PK have a great potential to enhance the efficacy of chemotherapy and radiotherapy [45-47].

\section{Conclusions}

This study showed the positive relationship between cMyc expression in highly metastatic human prostate and 
colon cancer cells and susceptibility to TRAIL-induced apoptosis, which indicated that TRAIL might be used as an effective therapeutic modality for advanced metastatic cancers overexpressing c-Myc. In addition, DMNB, a specific inhibitor of DNA-PK, potentiated TRAIL-induced cytotoxicity and apoptosis in relatively TRAIL-insensitive KM12 and PC3 cells and therefore functioned as a TRAIL sensitizer, which might be clinically useful for the treatment of relatively TRAIL-insensitive human cancers.

\section{Methods}

\section{Cell culture and Reagents}

The poorly metastatic primary human colorectal carcinoma KM12 cells were originally derived from a Dukes' B2 colon cancer. The highly liver-metastatic KM12L4A cells were derived from KM12 cells. Human androgenindependent PC3 prostate adenocarcinoma cells and PC3-MM2 cells, a variant of PC3 selected for their highly metastatic potential were used in this study. These four cell lines were provided by Professor IJ Fidler (MD Anderson, TX, USA). The cells were maintained in culture $\left(5 \% \mathrm{CO}_{2}\right.$ and $95 \%$ at $\left.37^{\circ} \mathrm{C}\right)$ as adherent monolayers in DMEM supplemented with $10 \%$ fetal bovine serum (FBS), sodium pyruvate, nonessential amino acids, L-glutamine, and vitamin solution. The recombinant human soluble TRAIL was obtained from R\&D Systems (Minneapolis, MN, USA). 4,5-dimethoxy-2nitrobenzaldehyde (DMNB) was purchased from Merck KgaA (Darmstadt, Germany).

\section{Cell Proliferation Assay (MTT assay)}

Cell proliferation was measured by counting viable cells by using the 3-(4,5-dimethylthiazol-2-yl)-2,5-diphenyltetrazolium bromide (MTT; Sigma Chemical Company, St. Louis, MO, USA) colorimetric dye-reduction method. Exponentially growing cells $\left(5 \times 10^{3}\right.$ cells/well $)$ were plated in a 96-well plate and incubated in growth medium treated with the indicated concentration of TRAIL and/or DMNB at $37^{\circ} \mathrm{C}$. After $96 \mathrm{~h}$, the medium was aspirated using centrifugation and MTT-formazan crystals solubilized in $100 \mu \mathrm{l}$ DMSO. The optical density of each sample at $570 \mathrm{~nm}$ was measured using ELISA reader. The optical density of the medium was proportional to the number of viable cells. Inhibition of proliferation was evaluated as a percentage of control growth (no drug in the medium). All experiments were repeated in at least two experiments in triplicate.

\section{Flow cytometry analysis}

Cells $\left(5 \times 10^{5}\right.$ cells/well $)$ treated with or without TRAIL (or DMNB) were centrifuged at $500 \times \mathrm{g}$, washed with phosphate-buffered saline (PBS), and resuspended in $500 \mu \mathrm{l}$ PBS. The cells were then incubated with $5 \mu \mathrm{l}$ mouse IgG, or anti-DR4 or -DR5 monoclonal mouse antibody (1:100; R\&D Systems, Minneapolis, MN, USA) for $2 \mathrm{~h}$. After washing with PBS, FITC-conjugated rabbit anti-mouse IgG (1:200; Sigma Chemical Co., St. Louis, MO, USA) was added to the cell suspension and incubated for $2 \mathrm{~h}$ on ice followed by washing with PBS. After rinsing, the samples were analyzed by flow cytometry using a FACSCalibur flow cytometer (Becton Dickinson, San Jose, CA, USA). The data were analyzed using the CellQuest program.

To determine whether TRAIL-induced apoptosis occurs through the death receptors, cells were pretreated with the TRAIL-R1 (anti-DR4) or TRAIL-R2 (anti-DR5) antibody $(0.5 \mu \mathrm{g} / \mathrm{ml}, \mathrm{R} \& \mathrm{D}$ Systems, Minneapolis, MN) $3 \mathrm{~h}$ before treatment with 2 and $10 \mathrm{ng} /$ $\mathrm{ml}$ TRAIL for $6 \mathrm{~h}$. In control experiments, cells were treated normal goat IgG (Sigma-Aldrich Corp., St Louis, MO, USA) before TRAIL treatment. Apoptosis was the measured by annexin $\mathrm{V}$ assay.

\section{Quantitative real-time RT-PCR}

Quantitative analysis of $\mathrm{FLIP}_{\mathrm{L} / \mathrm{S}}$ mRNA levels was performed by the SYBR Green real time PCR method using 2X Power SYBR ${ }^{\circledR}$ Green PCR Master Mix (Applied Biosystems, CA, USA) in a Bio-Rad iCycler \& iQ Real-time PCR systems (Bio-Rad, Hercules, CA, USA). An increase in the fluorescence of the reporter dye, SYBR green, during quantitative real-time RT-PCR is due to the SYBR green binding to double-stranded DNA. The sequences of forward and reverse primers for FLIP $_{L}$, FLIP $_{S}$ and $\beta$-actin (as loading control) are the following: FLIP $_{\mathrm{L}}$ (forward) 5'-TTCCAGGCTTTCGGTTTCTT-3' and (reverse) 5'-GTCCGAAACAAGGTGAGGGT-3'; FLIP $_{S}$ (forward) 5'-ACCCTCACCTTGTTTCGGAC-3' and (reverse) 5'-CTTTTGGATTGCTGCTTGGA-3'; and $\beta$-actin (forward) 5'-CAGAGCAAGAGAGGCATCCT-3' and (reverse) 5'-TTGAAGGTCTC AAACATGAT-3'. After initial denaturation step at $95^{\circ} \mathrm{C}$ for $10 \mathrm{~min}$, each amplification step was repeated 60 cycles with the following condition: denaturation at $95^{\circ} \mathrm{C}$ for $30 \mathrm{sec}$, annealing at $55^{\circ} \mathrm{C}$ for $60 \mathrm{sec}$ and extension at $60^{\circ} \mathrm{C}$ for $60 \mathrm{sec}$. Each sample was tested in triplicate, and gene expression levels were normalized to $\beta$-actin mRNA.

\section{Western blot and immunoprecipitation analysis}

Protein samples were separated by SDS-PAGE and blotted onto a nitrocellulose membrane (Hybond-ECL; GE Healthcare, Buckinghamshire, UK). The membrane was incubated with antibody as specified, followed by a secondary antibody conjugated with horseradish peroxidase. Specific antigen-antibody complexes were detected using enhanced chemiluminescence (PerkinElmer Life Sciences, MA, USA). Western blot analysis was performed with the following antibodies: Bax, caspase-3, 
PARP and Bcl-2, (Santa Cruz Biotechnology, CA, USA), Akt, phospho-Akt (Ser 473), caspase-8, caspase-9 (Cell signaling Technology, MA, USA), DNA-PKcs (Thermo Fisher Scientific, CA, USA), c-Myc, phospho-c-Myc (pMyc, Epitomics, CA, USA), and $\beta$-actin (SigmaAldrich, St. Louis, MO, USA). Secondary antibodies were obtained from GE Healthcare (Buckinghamshire, UK). For immunoprecipitation, whole cell or nuclear extracts from PC3 and PC3-MM2 cells were incubated with anti-DNA-PKcs or C-Myc antibody overnight at $4^{\circ}$ $\mathrm{C}$, and then protein G-Sepharose beads (Sigma-Aldrich Corp., St Louis, MO, USA) were added and constantly mixed for $4 \mathrm{~h}$. The beads were collected by centrifugation for $5 \mathrm{~min}$ at $15,000 \times \mathrm{g}$ and $4^{\circ} \mathrm{C}$, and washed 3 times with cold extraction buffer. The beads with immune complexes were boiled and electrophoresed on 8\% SDS-PAGE gels and analyzed by Western blotting using antibodies against c-Myc, pMyc or DNA-PKcs.

\section{siRNA Transfection}

The DNA-PKcs (5'-CAGUCUUAGUCCGGAUCAUdTdT-3'), c-Myc (5'-GACAGUGUCAGAGUCCUGAdTdT-3'), and control scrambled (5'-CUUCCCGA AAACUUGAGACdTdT-3') siRNAs were used in this study. Cells were transfected with $0.1 \mu \mathrm{M}$ siRNA for $48 \mathrm{~h}$ using oligofectamine according to the manufacturer's instructions (Invitrogen, Carlsbad, CA, USA). In brief, the siRNA/oligofectamine complex was added to cells $\left(2 \times 10^{5}\right.$ cells/well) that were seeded in 6-well plate. The cells were incubated for $4 \mathrm{~h}$ at $37^{\circ} \mathrm{C}$ in serum free DMEM medium and then FBS was added. After $48 \mathrm{~h}$, the cells were treated with TRAIL and collected for Western blot analysis to determine the levels of DNA-PKcs, c-Myc, and the indicated proteins.

\section{Apoptosis assay}

Untransfected control cells or transfected with the various siRNAs cells $\left(2 \times 10^{5}\right.$ cells $\left./ \mathrm{ml}\right)$ were treated with or without TRAIL and/or DMNB for the indicated times. The cells were centrifuged and resuspended in $500 \mu \mathrm{l}$ of a staining solution containing Annexin V fluorescein (FITC Apoptosis Detection Kit; BD Pharmingen, San Diego, CA, USA) and propidium iodide in PBS. After incubation at room temperature for $15 \mathrm{~min}$, the cells were analyzed by flow cytometry. Annexin V binds to cells that express phosphatidyl serine on the outer layer of their cell membrane, and propidium iodide stains the cellular DNA of cells with a compromised cell membrane. This allows for the discrimination of live cells (unstained with either fluorochrome) from apoptotic cells (stained only with Annexin V) and necrotic cells (stained with Annexin V and propidium iodide).

\section{Statistical analysis}

The results obtained were expressed as the mean \pm standard error (SE) from at least three independent experiments. The data were analyzed using the Student's t-test. $" p<0.05, * * p<0.01$, and ${ }^{* * * *} p<0.001$ were considered statistically significant in all experiments.

\section{Abbreviations}

TRAIL: tumor necrosis factor-related apoptosis-inducing ligand; DNA-PK: DNA-dependent protein kinase; siRNA: small interfering RNA; MTT: 3-(4, 5dimethylthiazol-2-yl)-2,5-diphenyltetrazolium bromide; DMNB: 4,5-dimethoxy2-nitrobenzaldehyde.

\section{Acknowledgements}

This study was supported by the Mid-career Researcher Program through an NRF grant funded by the MEST (No. 2009-0084444) and the National R\&D Program for Cancer Control, Ministry for Health, Welfare, and Family affairs, Republic of Korea (0920050).

\section{Author details}

'Department of Biochemistry, Pusan National University School of Medicine, Yangsan 626-870, South Korea. ${ }^{2}$ Research Center for Ischemic Tissue regeneration, Pusan National University School of Medicine, Yangsan 626870, South Korea. ${ }^{3}$ Department of Microbiology, College of Natural Sciences, Chang Won National University, Chang Won 641-773, South Korea.

\section{Authors' contributions}

HBK, MJK, DYK, JWL and JHB designed and conducted experiments as well data analysis. DWK participated in discussion of the data and draft of the manuscript. SHK and CDK equally participated in experimental design, coordination, data analysis and draft of the manuscript. All authors read and approved the final manuscript.

\section{Competing interests}

The authors declare that they have no competing interests.

Received: 27 November 2010 Accepted: 25 April 2011

Published: 25 April 2011

\section{References}

1. Rosa DD, Ismael G, Lago LD, Awada A: Molecular-targeted therapies: lessons from years of clinical development. Cancer Treat Rev 2008, 34:61-80.

2. Cusack JC Jr: Overcoming antiapoptotic responses to promote chemosensitivity in metastatic colorectal cancer to the liver. Ann Surg Oncol 2003, 10:852-862.

3. Sorscher SM: Biological therapy update in colorectal cancer. Expert Opin Biol Ther 2007, 7:509-519.

4. Mimeault M, Batra SK: Novel therapies against aggressive and recurrent epithelial cancers by molecular targeting tumor- and metastasisinitiating cells and their progenies. Anticancer Agents Med Chem 2010, 10:137-151.

5. Rudmik LR, Magliocco AM: Molecular mechanisms of hepatic metastasis in colorectal cancer. J Surg Oncol 2005, 92:347-359.

6. Merino D, Lalaoui N, Morizot A, Solary E, Micheau O: TRAIL in cancer therapy: present and future challenges. Expert Opin Ther Targets 2007, 11:1299-1314.

7. Rowinsky EK: Targeted induction of apoptosis in cancer management: the emerging role of tumor necrosis factor-related apoptosis-inducing ligand receptor activating agents. J Clin Oncol 2005, 23:9394-9407.

8. Kruyt FA: TRAIL and cancer therapy. Cancer Lett 2008, 263:14-25.

9. Fernandez T, Torres MJ, R RP, Fuentes MS, Robles S, Mayorga C, Blanca M: Decrease of selective immunoglobulin $E$ response to amoxicillin despite repeated administration of benzylpenicillin and penicillin V. Clin Exp Allergy 2005, 35:1645-1650.

10. Nieminen Al, Partanen Jl, Klefstrom J: c-Myc blazing a trail of death: coupling of the mitochondrial and death receptor apoptosis pathways by c-Myc. Cell Cycle 2007, 6:2464-2472. 
11. Hoffman B, Liebermann DA: Apoptotic signaling by c-MYC. Oncogene 2008, 27:6462-6472.

12. Nieminen Al, Partanen Jl, Hau A, Klefstrom J: c-Myc primed mitochondria determine cellular sensitivity to TRAlL-induced apoptosis. EMBO J 2007, 26:1055-1067.

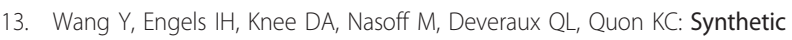
lethal targeting of MYC by activation of the DR5 death receptor pathway. Cancer Cell 2004, 5:501-512.

14. Um JH, Kwon JK, Kang CD, Kim MJ, Ju DS, Bae JH, Kim DW, Chung BS, Kim SH: Relationship between antiapoptotic molecules and metastatic potency and the involvement of DNA-dependent protein kinase in the chemosensitization of metastatic human cancer cells by epidermal growth factor receptor blockade. J Pharmacol Exp Ther 2004, 311:1062-1070.

15. An J, Yang DY, Xu QZ, Zhang SM, Huo YY, Shang ZF, Wang Y, Wu DC, Zhou PK: DNA-dependent protein kinase catalytic subunit modulates the stability of c-Myc oncoprotein. Mol Cancer 2008, 7:32.

16. Qiao M, Iglehart JD, Pardee AB: Metastatic potential of 21T human breast cancer cells depends on Akt/protein kinase B activation. Cancer Res 2007, 67:5293-5299.

17. Kim SH, Ricci MS, El-Deiry WS: MCl-1: a gateway to TRAIL sensitization. Cancer Res 2008, 68:2062-2064.

18. Ricci MS, Kim SH, Ogi K, Plastaras JP, Ling J, Wang W, Jin Z, Liu YY, Dicker DT, Chiao PJ, et al: Reduction of TRAIL-induced Mcl-1 and CIAP2 by c-Myc or sorafenib sensitizes resistant human cancer cells to TRAILinduced death. Cancer Cell 2007, 12:66-80.

19. Ricci MS, Jin Z, Dews M, Yu D, Thomas-Tikhonenko A, Dicker DT, ElDeiry WS: Direct repression of FLIP expression by c-myc is a major determinant of TRAIL sensitivity. Mol Cell Biol 2004, 24:8541-8555.

20. lijima S, Teraoka H, Date T, Tsukada K: DNA-activated protein kinase in Raji Burkitt's lymphoma cells. Phosphorylation of c-Myc oncoprotein. Eur J Biochem 1992, 206:595-603.

21. Lane D, Robert V, Grondin R, Rancourt C, Piche A: Malignant ascites protect against TRAIL-induced apoptosis by activating the PI3K/Akt pathway in human ovarian carcinoma cells. Int J Cancer 2007, 121:1227-1237.

22. Larribere L, Khaled M, Tartare-Deckert S, Busca R, Luciano F, Bille K, Valony $\mathrm{G}$, Eychene A, Auberger P, Ortonne JP, et al: PI3K mediates protection against TRAlL-induced apoptosis in primary human melanocytes. Cell Death Differ 2004, 11:1084-1091.

23. Asakuma J, Sumitomo M, Asano T, Hayakawa M: Selective Akt inactivation and tumor necrosis actor-related apoptosis-inducing ligand sensitization of renal cancer cells by low concentrations of paclitaxel. Cancer Res 2003, 63:1365-1370.

24. Xu J, Zhou JY, Wei WZ, Wu GS: Activation of the Akt survival pathway contributes to TRAIL resistance in cancer cells. PLOS One 2010, 5:e10226.

25. Feng J, Park J, Cron P, Hess D, Hemmings BA: Identification of a PKB/Akt hydrophobic motif Ser-473 kinase as DNA-dependent protein kinase. J Biol Chem 2004, 279:41189-41196.

26. Teraoka H, Yumoto $Y$, Watanabe $F$, Tsukada $K$, Suwa A, Enari M, Nagata S: CPP32/Yama/apopain cleaves the catalytic component of DNAdependent protein kinase in the holoenzyme. FEBS Lett 1996, 393:1-6.

27. Durant S, Karran P: Vanillins-a novel family of DNA-PK inhibitors. Nucleic Acids Res 2003, 31:5501-5512.

28. Seo SB, Hur JG, Kim MJ, Lee JW, Kim HB, Bae JH, Kim DW, Kang CD, Kim SH: TRAIL sensitize MDR cells to MDR-related drugs by down-regulation of P-glycoprotein through inhibition of DNA-PKcs/Akt/GSK-3beta pathway and activation of caspases. Mol Cancer 2010, 9:199.

29. Park SJ, Bijangi-Vishehsaraei K, Safa AR: Selective TRAIL-triggered apoptosis due to overexpression of TRAIL death receptor 5 (DR5) in Pglycoprotein-bearing multidrug resistant CEM/VBL1000 human leukemia cells. Int J Biochem Mol Biol 2010, 1:90-100.

30. Hall MA, Cleveland JL: Clearing the TRAIL for Cancer Therapy. Cancer Cell $2007,12: 4-6$

31. Pelengaris S, Khan M, Evan G: c-MYC: more than just a matter of life and death. Nat Rev Cancer 2002, 2:764-776.

32. Hueber AO, Zornig M, Lyon D, Suda T, Nagata S, Evan Gl: Requirement for the CD95 receptor-ligand pathway in c-Myc-induced apoptosis. Science 1997, 278:1305-1309
33. Klefstrom J, Arighi E, Littlewood T, Jaattela M, Saksela E, Evan Gl, Alitalo K: Induction of TNF-sensitive cellular phenotype by c-Myc involves p53 and impaired NF-kappaB activation. EMBO J 1997, 16:7382-7392.

34. Han J, Goldstein LA, Gastman BR, Rabinowich H: Interrelated roles for Mcl1 and BIM in regulation of TRAIL-mediated mitochondrial apoptosis. $J$ Biol Chem 2006, 281:10153-10163.

35. Kataoka T, Tschopp J: N-terminal fragment of c-FLIP(L) processed by caspase 8 specifically interacts with TRAF2 and induces activation of the NF-kappaB signaling pathway. Mol Cell Biol 2004, 24:2627-2636.

36. Shintani S, Mihara M, Li C, Nakahara Y, Hino S, Nakashiro K, Hamakawa H: Up-regulation of DNA-dependent protein kinase correlates with radiation resistance in oral squamous cell carcinoma. Cancer Sci 2003, 94:894-900.

37. Stronati L, Gensabella G, Lamberti C, Barattini P, Frasca D, Tanzarella C, Giacobini S, Toscano MG, Santacroce C, Danesi DT: Expression and DNA binding activity of the Ku heterodimer in bladder carcinoma. Cancer 2001, 92:2484-2492.

38. Tonotsuka N, Hosoi Y, Miyazaki S, Miyata G, Sugawara K, Mori T, Ouchi N, Satomi S, Matsumoto Y, Nakagawa K, et al: Heterogeneous expression of DNA-dependent protein kinase in esophageal cancer and normal epithelium. Int J Mol Med 2006, 18:441-447.

39. Moll U, Lau R, Sypes MA, Gupta MM, Anderson CW: DNA-PK, the DNAactivated protein kinase, is differentially expressed in normal and malignant human tissues. Oncogene 1999, 18:3114-3126.

40. An J, Xu QZ, Sui JL, Bai B, Zhou PK: Downregulation of c-myc protein by siRNA-mediated silencing of DNA-PKcs in HeLa cells. Int $J$ Cancer 2005, 117:531-537.

41. Puduvalli VK, Sampath D, Bruner JM, Nangia J, Xu R, Kyritsis AP: TRAILinduced apoptosis in gliomas is enhanced by Akt-inhibition and is independent of JNK activation. Apoptosis 2005, 10:233-243.

42. Lee YJ, Froelich CJ, Fujita N, Tsuruo T, Kim JH: Reconstitution of caspase-3 confers low glucose-enhanced tumor necrosis factor-related apoptosisinducing ligand cytotoxicity and Akt cleavage. Clin Cancer Res 2004, 10:1894-1900.

43. Affar EB, Germain M, Winstall E, Vodenicharov M, Shah RG, Salvesen GS, Poirier GG: Caspase-3-mediated processing of poly(ADP-ribose) glycohydrolase during apoptosis. J Biol Chem 2001, 276:2935-2942.

44. Graham KL, Gustin KE, Rivera C, Kuyumcu-Martinez NM, Choe SS, Lloyd RE, Sarnow P, Utz PJ: Proteolytic cleavage of the catalytic subunit of DNAdependent protein kinase during poliovirus infection. J Virol 2004, 78:6313-6321.

45. Kim SH, Um JH, Dong-Won B, Kwon BH, Kim DW, Chung BS, Kang CD: Potentiation of chemosensitivity in multidrug-resistant human leukemia CEM cells by inhibition of DNA-dependent protein kinase using wortmannin. Leuk Res 2000, 24:917-925.

46. Ismail IH, Martensson S, Moshinsky D, Rice A, Tang C, Howlett A, McMahon G, Hammarsten O: SU11752 inhibits the DNA-dependent protein kinase and DNA double-strand break repair resulting in ionizing radiation sensitization. Oncogene 2004, 23:873-882.

47. Zhao Y, Thomas HD, Batey MA, Cowell IG, Richardson CJ, Griffin RJ, Calvert AH, Newell DR, Smith GC, Curtin NJ: Preclinical evaluation of a potent novel DNA-dependent protein kinase inhibitor NU7441. Cancer Res 2006, 66:5354-5362

\section{doi:10.1186/1476-4598-10-46}

Cite this article as: Kim et al: High susceptibility of metastatic cells derived from human prostate and colon cancer cells to TRAIL and sensitization of TRAIL-insensitive primary cells to TRAIL by $4,5-$ dimethoxy-2-nitrobenzaldehyde. Molecular Cancer 2011 10:46. 